\title{
Changes in European greenhouse gas and air pollutant emissions 1960-2010: decomposition of determining factors
}

\author{
Peter Rafaj • Markus Amann • José Siri • \\ Henning Wuester
}

Received: 14 December 2012 / Accepted: 17 June 2013 / Published online: 4 July 2013

(C) Springer Science+Business Media Dordrecht 2013

\begin{abstract}
This paper analyses factors that contributed to the evolution of $\mathrm{SO}_{2}, \mathrm{NO}_{\mathrm{x}}$ and $\mathrm{CO}_{2}$ emissions in Europe from 1960 to 2010. Historical energy balances, along with population and economic growth data, are used to quantify the impacts of major determinants of changing emission levels, including energy intensity, conversion efficiency, fuel mix, and pollution control. Time series of emission levels are compared for countries in Western and Eastern Europe, throwing light on differences in the importance of particular emissiondriving forces. Three quarters of the decline in $\mathrm{SO}_{2}$ emissions in Western Europe resulted from a combination of reduced energy intensity and improved fuel mix, while dedicated endof-pipe abatement measures played a dominant role in the reduction of $\mathrm{NO}_{\mathrm{x}}$ emissions. The increase in atmospheric emissions in Eastern Europe through the mid-1990s was associated with the growth of energy-intensive industries, which off-setted the positive impact of better fuel quality and changes in fuel mix. A continuous decrease in energy intensity and higher conversion efficiencies have been the main factors responsible for the moderate rate of growth of European $\mathrm{CO}_{2}$ emissions.
\end{abstract}

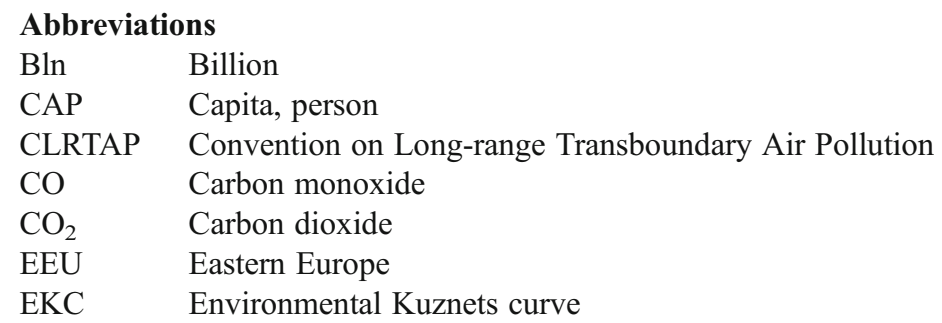

This article is part of a Special Issue on "Third International Workshop on Uncertainty in Greenhouse Gas Inventories" edited by Jean Ometto and Rostyslav Bun.

P. Rafaj $(\bowtie) \cdot$ M. Amann $\cdot$ J. Siri

International Institute for Applied Systems Analysis (IIASA), Schlossplatz 1, 2361 Laxenburg, Austria e-mail: rafaj@iiasa.ac.at

H. Wuester

United Nations Framework Convention on Climate Change (UNFCCC), Martin-Luther-King-Str. 8, 53175 Bonn, Germany 


$\begin{array}{ll}\text { EMEP } & \text { European Monitoring and Evaluation Programme } \\ \text { EU } & \text { European Union } \\ \text { FGD } & \text { Flue gas desulphurisation } \\ \text { GAINS } & \text { Greenhouse gas and Air pollution Interactions And Synergies model } \\ \text { GDP } & \text { Gross domestic product } \\ \text { GHG } & \text { Greenhouse gas } \\ \text { Gt } & \text { Giga tonnes } \\ \text { IEA } & \text { International Energy Agency } \\ \text { J } & \text { Joule (M Mega } 10^{6}, \text { G Giga } 10^{9}, \text { P Peta } 10^{15} \text { ) } \\ \text { Mt } & \text { Mega tonnes } \\ \text { NO } & \text { Nitrogen oxides } \\ \text { PM } & \text { Particulate matter } \\ \text { PPP } & \text { Purchasing power parity } \\ \text { RAINS } & \text { Regional Air pollution Information and Simulation model } \\ \text { SO } & \text { Sulfur dioxide } \\ \text { UNFCCC } & \text { United Nations Framework Convention on Climate Change } \\ \text { US- } \$ & \text { US dollar } \\ \text { VOCs } & \text { Volatile organic compounds } \\ \text { WEU } & \text { Western Europe }\end{array}$

\section{Introduction}

Over the last century, Europe has experienced a long phase of dynamic growth in emissions of air pollutants and greenhouse gases. However, the 1970's saw a dramatic reduction in Western European $\mathrm{SO}_{2}$ emissions, followed by a clear decline in emissions of $\mathrm{NO}_{\mathrm{x}}$ a decade later. In contrast, the growth rate of $\mathrm{CO}_{2}$ emissions has not changed.

There are various hypotheses concerning the underlying factors and driving forces responsible for these observed patterns in air pollutant emissions. For instance, economists have proposed the existence of an environmental Kuznets curve (EKC), under which pollution increases at low levels of income up to a turning point beyond which it decreases, in reference to the original Kuznets curve for economic inequality (Kuznets 1955). Reasons for such an inverted U-shaped relationship are hypothesized to include income-driven changes in: (1) the composition of production and/or consumption; (2) consumer preference for environmental quality; (3) institutions that are needed to internalize externalities; and/or (4) increasing returns to scale associated with pollution abatement. Other voices point to the structural changes in energy and industrial systems that resulted from the increase in global energy prices that followed the 1970's oil crisis, which also reduced the consumption of the most-polluting fuels. Environmentalists often emphasize the elaborate national and international frameworks of environmental legislation through which European countries agreed to take dedicated measures to reduce their emissions, inter alia by applying advanced end-of-pipe emission control technologies (Hordijk and Amann 2007).

We explore and quantify the impacts of such driving forces on changes in a set of selected emission species $\left(\mathrm{SO}_{2}, \mathrm{NO}_{\mathrm{x}}\right.$ and $\left.\mathrm{CO}_{2}\right)$ in Europe between 1960 and 2010, developing two identities that explain observed emissions as the product of key factors. In keeping with the hypothesized EKC, the first identity incorporates three terms: population, per capita income, and per capita emissions. The second identity decomposes the latter into macroeconomic changes, changes in the energy system, and dedicated environmental policy interventions. We assess the evolution of these factors between 1960 and 2010 and attempt to associate observed variations with important exogenous events. 
We then estimate the combined impacts of these factors on emission trajectories for Western and Eastern Europe, respectively. While specific factors differ from country to country, this analysis should improve understanding of the relative importance of driving forces in European atmospheric pollution trends: economic welfare (as suggested by the EKC), emerging technological and structural factors, and/or awareness of the harmful environmental impacts of pollution, as reflected in pan-European environmental policies.

The following section briefly reviews the literature on the EKC, summarizing some of the motivations for this study. Section 3 describes our methods and data. Section 4 discusses the evolution of driving forces and resulting emissions of $\mathrm{SO}_{2}, \mathrm{NO}_{\mathrm{x}}$ and $\mathrm{CO}_{2}$ from 1960 to 2010; it provides a theoretical basis for the decomposition analysis and highlights the most important empirical results, including detailed findings for selected countries. Section 5 places the quantitative assessment of the main determinants within a broader policy context. The final section presents conclusions and discusses some policy implications of the main findings.

\section{The environmental Kuznets curve}

The EKC hypothesis emerged from the debate over the fundamental determinants of longterm improvements in the environment, and particularly from a growing literature on the relationship between pollution and economic growth. It suggests that there is an inverted Ushaped relationship between environmental quality and wealth, such that pollution first increases with economic growth, but then decreases once a certain level of wealth has been attained. Most empirical literature has focused on $\mathrm{SO}_{2}$ emissions, often making use of urban air quality data, with few studies dedicated to other pollutant species. Existing analyses, moreover, rarely account sufficiently for all relevant aspects of the environmental problems under consideration, or address the underlying causes of the hypothesized relationships. A refined examination of the determinants and effects of changes in air pollutant emissions may help to explain to what extent and through what mechanism economic development influences environmental quality, as well as the role of other factors. Thirty years of international atmospheric protection efforts have generated sufficient data to re-examine the EKC hypothesis and draw lessons for future policy (Vestreng et al. 2007). In particular, publicly available databases contain information about both emission control measures implemented in European countries and energy consumption, which can be linked to data on environmental effects and economic development. Such analyses are especially important in a context where it has been argued that economic growth, in and of itself, will eventually reduce environmental degradation (Andreoni and Levinson 2001). Here, we briefly review the theoretical basis and empirical evidence for the EKC.

\subsection{Theoretical work}

Gruver (1976) developed a neoclassical growth model with optimized investment into either productive capital or pollution control capital. Whereas productive capital can be used for several purposes (to increase consumption or produce more capital of either type), pollution control capital only enters the utility function through environmental improvements. Given this framework and the convex neoclassical utility function, it is optimal to focus on the build-up of productive capital, neglecting the environment, during an initial phase of development and then, with decreasing marginal utility of consumption, switch to investment aimed at reducing pollution. Selden and Song (1995) describe similar optimal growth, 
but with only one investment category and with expenditure on pollution abatement decreasing consumption directly. This provides the basis for the "J-curve for abatement," where at low consumption, abatement expenditure is also minimal or zero; it thus directly explains the inverted U-curve for pollution on the basis of the assumed utility function.

Andreoni and Levinson (2001) briefly survey other theoretical efforts to explain the EKC and develop their own simple microeconomic model. They show that the observed incomepollution relationship can be explained by abatement technology with increasing returns to scale, as is the case for technologies requiring large capital investments. In a critical review of the EKC theory, Stern (2004) concludes that classic EKC results may not adequately explain emission pathways, because the underlying statistical analysis is not robust and there is only weak evidence for a coherent relationship between pollution and income. The study suggests that structural factors contribute to declining pollution rates, but are less influential than the time-related effects of targeted emission abatement measures.

\subsection{Empirical studies}

Early papers often cited in reference to the EKC include Shafik (1994), Selden and Song (1994) and Grossman and Krueger (1995). These studies use panel data for several countries and years in regression analyses; however, they do not explicitly consider the determinants of the relationship between pollution and income. Shafik (1994) makes use of a broad range of environmental data, including ambient $\mathrm{PM}, \mathrm{SO}_{2}$ and $\mathrm{CO}_{2}$ levels, deforestation, clean water supply, urban sanitation, $\mathrm{O}_{2}$ and fecal coliforms in rivers, and municipal waste. For these quality indicators, relationships are derived with respect to per capita income; in some cases these fit the EKC hypothesis, but in others, monotonically decreasing or increasing pollution trends predominate. The study also notes a trend toward lower pollution maxima over time (e.g., annual decreases in the maximum ambient values of $2 \%$ for PM and $5 \%$ for $\mathrm{SO}_{2}$, respectively), which is attributed to technological improvement. The need for research on both structural and policy determinants of changes in environmental quality is emphasized. Selden and Song (1994) study emissions of $\mathrm{SO}_{2}, \mathrm{PM}, \mathrm{NO}_{\mathrm{x}}$, and $\mathrm{CO}$ and observe a similar pattern, although they find that pollution begins decreasing at higher levels of per capita income. They attribute this to cheaper costs of abatement for urban air pollution, for instance through the installation of high stacks - this is, at least for PM, a questionable assumption, given its dispersion behaviour. They use their model, in conjunction with country growth rates, to forecast global emission levels. Grossman and Krueger (1995) examine urban concentrations of atmospheric $\mathrm{SO}_{2}$ and $\mathrm{PM}$ as well as water quality in river basins, observing a relationship which supports the EKC hypothesis, though they consider only two countries (Canada and the USA) in the high (i.e., > US-\$16,000/year) income range.

Kaufmann et al. (1998) find an inverted U-shaped relationship between the spatial intensity of economic activity and atmospheric concentrations of $\mathrm{SO}_{2}$, whereas for per capita GDP and $\mathrm{SO}_{2}$ concentrations the relationship appears U-shaped. They argue that per capita GDP acts merely as a proxy for the spatial intensity of economic activity, which dominates the true association, yet fail to provide any convincing argument for this assertion. For instance, they ignore the acidifying properties of $\mathrm{SO}_{2}$, which were the main driving force for its abatement in Europe after 1980. This factor may largely explain the observed phenomenon: deposition of sulphur compounds will tend to be more harmful (i.e., more likely to exceed critical loads for acidification) if concentrated within a small area.

De Bruyn et al. (1998) criticize the econometrics of earlier studies and re-examine the literature that associates the decline in the material-intensity of GDP with economic growth. 
As they lack the data to conduct a decomposition analysis, they estimate a reduced-form regression model for time series of $\mathrm{SO}_{2}, \mathrm{NO}_{\mathrm{x}}$, and $\mathrm{CO}_{2}$ emissions for Western Germany, Netherlands, the UK and the USA between 1960 and 1993. In contrast with the expectations of the EKC hypothesis, their model suggests that emissions tend to increase with economic growth. Observed reductions result from the structural and technological factors that dominated subsequent to the low growth rates of the early 1970s. To interpret the results in terms of sustainability, they suggest linking the data to critical loads for acidification and eutrophication. Several other studies (e.g., Viguier 1999; Bruvoll and Medin 2003; Markandya et al. 2006) support the hypothesis that the energy- and material-intensity of GDP behave as inverted U-shaped functions of per capita income. Cole (2000) shows that the EKC can be explained by the cleaner composition of manufacturing and falling share of manufacturing output in GDP with income growth.

Stern and Common (2001) survey the empirical literature on the relationship of $\mathrm{SO}_{2}$ with income. Making use of a longer (1850-1990) time series of global sulphur emissions, they find that the EKC exists only when the sample is limited to high-income countries. For the global sample, $\mathrm{SO}_{2}$ emissions per capita are a monotonic function of income, and reductions in emissions are time-related rather than income-related. They identify events - such as the adoption of the first sulphur Protocol to the Convention on Long-range Transboundary Air Pollution (CLRTAP) (UN-ECE 1985) - as possible causes of this time-dependency. In more recent work based on the current evolution of emissions in China and elsewhere, Stern (2006) concludes that although air pollutants tend to increase with rising income, they decrease over time as a result of rapid technological change, suggesting that low income levels do not prevent the adoption of abatement technologies.

\subsection{Motivation for this study}

The picture that emerges from this brief literature survey is that, while there is some evidence that supports the EKC, especially for air pollutants like $\mathrm{SO}_{2}$, the empirical and theoretical basis for this relationship is rather weak. There is stronger evidence suggesting that some of the underlying factors that determine emissions, energy consumption or structural change follow a Kuznets-type curve, whereas the deployment of dedicated mitigation measures and policies is likely independent of affluence. This study attempts to isolate these factors and relate them to economic growth. The impacts of driving forces behind changes in emissions are expected to be pollutant-specific, therefore we separately consider $\mathrm{SO}_{2}$ (emitted mainly from large stationary sources), $\mathrm{NO}_{\mathrm{x}}$ (primarily from vehicle engines), and $\mathrm{CO}_{2}$ (the dominant climate forcing agent, for which there were no end-of-pipe controls used in the past). We examine the effects of determining factors on time series for two subregions in Europe that experienced very different levels of wealth, technological advancement and environmental awareness.

\section{Methods}

The literature describes many alternative methods for carrying out a decomposition analysis of emission trends (Ang and Zhang 2000). Our model for the evaluation of determinants for emission changes is based on a simplified additive form of the index decomposition analysis. Detailed explanation of this method is provided by Hoekstra and van den Bergh (2003). The following sections present our basic assumptions made for the decomposition, and describe the datasets used in calculations. 


\subsection{Two identities to explain observed emissions}

We examine the evolution of European emissions of $\mathrm{SO}_{2}, \mathrm{NO}_{\mathrm{x}}$ and $\mathrm{CO}_{2}$ as the product of the following three determinants:

$$
\text { Emissions }=\text { Population } \cdot\left(\frac{G D P}{\text { Population }}\right) \cdot\left(\frac{\text { Emissions }}{G D P}\right),
$$

where GDP is Gross Domestic Product, a standard measure for economic output. Emissions of a given substance are thus a function of population, economic affluence (GDP/Population) and the emission intensity of the economy (Emissions/GDP). According to the EKC hypothesis, the third term should take the form of an inverse U-shaped curve, emerging as a composite of autonomous technological progress, structural changes in national economies, behavioural changes and dedicated environmental policies.

To evaluate the importance of these individual components, we extend this identity, and decompose the last term into three factors, as follows:

$$
\text { Emissions }=\text { Population } \cdot\left(\frac{G D P}{\text { Population }}\right) \cdot\left(\frac{\text { Energy }_{G D}}{G D P} \cdot \sum_{i}\left(\frac{\text { Fuel }_{i}}{\text { Energy }}\right) \cdot\left(\frac{\text { Emissions }_{\text {Fuel }}}{\text { Fun }_{i}}\right) .\right.
$$

Resulting emissions are thus further dependent on the energy intensity of the economy (Energy/GDP), i.e., the primary energy required per unit of GDP, on the fuel mix in each sector (i) $\left(\right.$ Fuel $_{i} /$ Energy $)$, and on the emission intensities of different fuels (Emissions/Fuel $_{i}$ ). The additive form decomposes the difference in emissions between time $t$ and $t-1$ into three determinant effects:

$$
\text { Emissions }^{t}-\text { Emissions }^{t-1}=\text { Factor(1)effect }+ \text { Factor(2)effect }+ \text { Factor(3)effect }
$$

These factors capture the key drivers that affect emissions, specifically:

1) overarching economic and/or energy intensity changes resulting from industrial sectoral restructuring, technological progress, energy efficiency improvements and behavioural changes;

2) alterations in the structure of the energy system, wherein emissions are critically determined by fuel mix changes due to, e.g., fuel switching in response to variation in relative fuel-prices;

3) dedicated application of end-of-pipe emission control measures in response to environmental legislation.

Our formulation extends the 'Kaya identity' that expresses emissions of $\mathrm{CO}_{2}$ as the product of four inputs: population, GDP per capita, energy use per unit of GDP and carbon emissions per unit of energy consumed (Kaya and Yokobori 1997; Waggoner and Ausubel 2002). This extension is useful in isolating the impacts of dedicated environmental policy interventions, of particular importance for emissions of the air pollutants $\mathrm{SO}_{2}$ and $\mathrm{NO}_{\mathrm{x}}$, for which highly effective end-of-pipe measures exist.

We analyse the development of these factors from 1960 to 2010, quantifying their contribution to observed changes in $\mathrm{SO}_{2}, \mathrm{NO}_{\mathrm{x}}$ and $\mathrm{CO}_{2}$ emissions in Europe. These emission species are selected, inter alia, for their environmental significance, extensive documentation in the literature, and because of the availability of reliable data, needed for 
the decomposition analysis. We compute hypothetical emission scenarios or trajectories for the study period in which we keep one or several of these factors at the level observed for a selected base year (i.e., 1960) while varying others, as follows:

I. First, a hypothetical upper limit for emissions over time is calculated, assuming that the emission intensities of GDP remain unchanged. Such an emission path would follow from income (GDP) growth, given constant energy intensity of GDP, unchanged fuel mix, and no emission control measures beyond those implemented in the base year; thus:

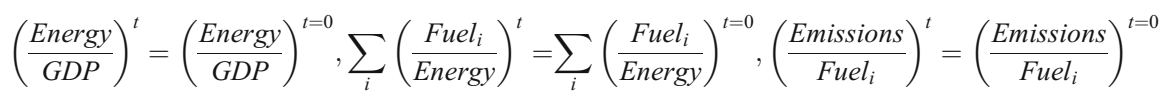

This trajectory reflects only changes in real-term GDP using purchasing power parity (PPP), thus constituting a reference against which the effects of other factors can be quantified.

II. In the following step, an emission trajectory is estimated using data on the real development of total energy consumption, but keeping fuel mix and emission factors for each fuel type constant at the base year level. Comparing this to the first trajectory reveals the impact on emissions of decoupling GDP from energy consumption. Changes in the energy intensities of GDP result from shifts in the sectoral composition of GDP as well as from efficiency improvements in energy systems.

III. Third, a hypothetical emissions time trend is calculated that accounts for changes in fuel mix, while keeping emission factors for each fuel type unchanged with respect to the base year value. A corollary condition is that the shares of all fuels must add up to one (i.e., $\sum_{i}$ Fuel $_{i} /$ Energy $=1$ ). Comparison of this scenario with the trajectory II above quantifies the impacts of fuel substitution (e.g., the replacement of coal by natural gas) on emissions. In some cases, fuel substitution came about in response to environmental legislation, but other factors were often involved, e.g., cost minimization, convenience, accessibility of energy grids and infrastructure.

IV. Finally, the contribution of dedicated emission control measures to total emission changes is derived in a similar way from a fourth trajectory, which tracks actual emissions by incorporating all driving factors, including the changes in emission factors for each fuel type in each sector. Emission factors are determined by the removal efficiency (Eff) of an abatement measure adopted at a specific rate $(X)$ :

$$
\text { Emission factor }=\left(\frac{\text { Emissions }^{t}}{\text { Fuel }_{i}}\right)^{\cdot} \cdot(1-\text { Eff }) \cdot X^{t}
$$

A comparison of the differences among these trajectories reveals the impact on emissions, respectively, of overall economic growth, the decoupling between GDP and energy use, changes in the fuel mix of total energy consumption, and the application of dedicated control measures. As reported by Rafaj et al. (2012), this methodology may be applied to the decomposition of emission trends for a range of other air pollutants 
(ammonia, fine particles, VOCs) ${ }^{1}$ or short-lived greenhouse gases (methane, ozone), not addressed in this study.

\subsection{Data sources}

This analysis examines emission changes within the 50-year period from 1960 to 2010 at five-year intervals. It distinguishes between two regions: Western Europe (WEU), comprising the 15 EU members prior to 2004, Switzerland and Norway; and Eastern Europe (EEU), including the 12 EU members that joined after 2004, the Balkan countries, Turkey, Belarus, Ukraine and Moldova (Fig. 1). ${ }^{2}$

As $\mathrm{SO}_{2}, \mathrm{NO}_{\mathrm{x}}$ and $\mathrm{CO}_{2}$ emissions originate almost entirely from the combustion of energy carriers, emission estimates are primarily based on statistical energy data and fuel balances. For most countries, energy statistics from the International Energy Agency (IEA 2009a, b, c, d) have been used for 1960-2005. For some countries of the former Soviet Union, missing statistical data for 1960-1990 have been extracted from the databases of two models: GAINS and its predecessor, RAINS (Amann 1990). Energy consumption for 2010 is based on the projections developed for the revision of the National Emission Ceiling Directive as implemented within the GAINS model (Capros et al. 2008). These sources also provided data on factors that contribute to autonomous emission reductions, such as GDP, energy intensity and population growth. However, because data on the efficiency of end-use devices and appliances is not provided, these factors are treated in aggregate. Emissions of $\mathrm{SO}_{2}$ and $\mathrm{NO}_{\mathrm{x}}$ are calculated for nine fuel categories in five economic sectors, as summarized in Table 1.

Emission factors for 1960 and subsequent years are extracted from the databases of the RAINS and GAINS models and, if necessary, adjusted such that resulting emissions match the official national estimates reported to the European Monitoring and Evaluation Programme (EMEP) under CLRTAP $^{3}$ (EMEP 2009). Figures reported by Mylona (1996) and Schöpp et al. (2003) are used to fill in missing data points. Emissions for 2010 are abstracted from the GAINS baseline scenario reported by Amann et al. (2008).

$\mathrm{CO}_{2}$ emissions are calculated on the basis of total primary energy supply according to IEA energy balances (IEA 2009a, b). In contrast to $\mathrm{SO}_{2}$ and $\mathrm{NO}_{\mathrm{x}}$, international aviation is not included as a source in estimates of $\mathrm{CO}_{2}$ emissions, but emissions from non-energy use of fossil fuels (e.g., asphalt production or chemical feedstock) are taken into account. Resulting $\mathrm{CO}_{2}$ emissions have been adjusted to the estimates reported by the IEA (2010).

\footnotetext{
${ }^{1}$ Ammonia emissions originate mainly from agricultural activities, such that temporal changes are driven by different forces than for more energy-related pollutants. Economic output of the agricultural sector, levels of primary agricultural production (e.g., livestock numbers), and the structural composition of livestock are used in the decomposition analysis.

${ }^{2}$ WEU thus includes 17 countries: Austria, Belgium, Denmark, Finland, France, Germany, Greece, Ireland, Italy, Luxembourg, Netherlands, Norway Portugal, Spain, Sweden, Switzerland and the United Kingdom; EEU comprises 22 countries: Albania, Belarus, Bosnia and Herzegovina, Bulgaria, Croatia, Cyprus, Czech Republic, Estonia, Hungary, Latvia, Lithuania, Macedonia, Malta, Moldova, Montenegro, Poland, Romania, Serbia, Slovakia, Slovenia, Turkey and Ukraine.

${ }^{3} \mathrm{SO}_{2}$ and $\mathrm{NO}_{\mathrm{x}}$ emission data from EMEP comprise gap-filled and gridded data based, for reasons of consistency, on official reported data supplemented by expert estimates for missing and/or low quality measurements.
} 


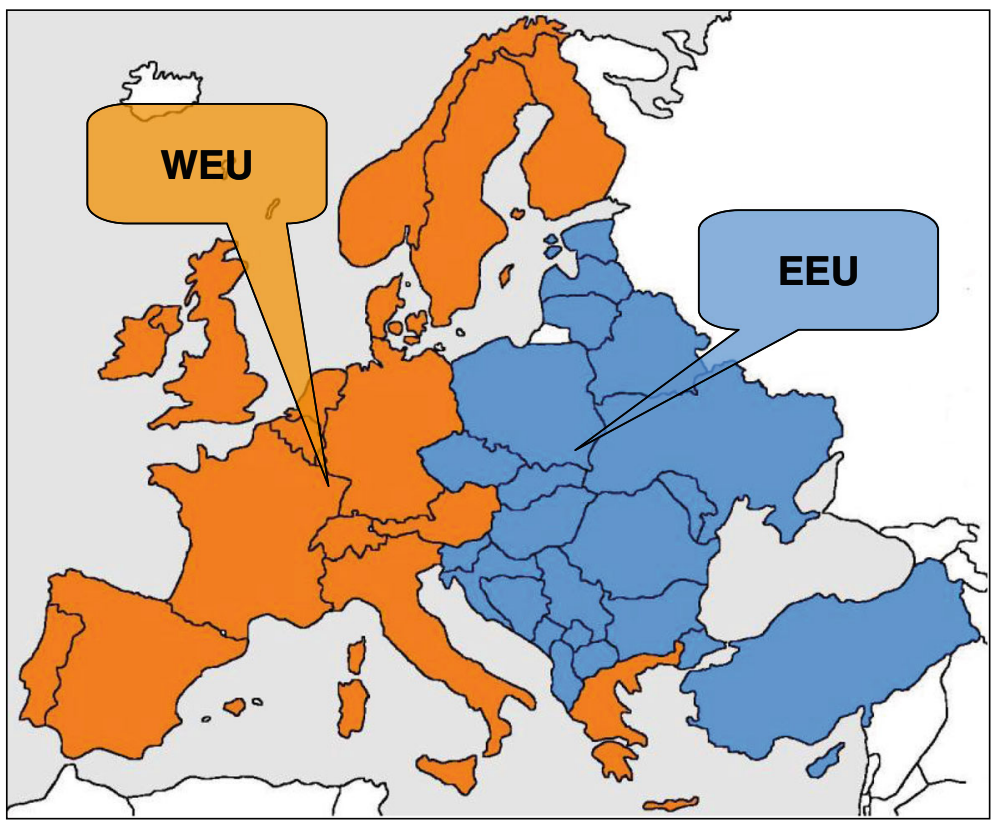

Fig. 1 Geographical coverage of emission calculations

The decomposition analysis of emission changes in this paper addresses only emissions from fuel combustion, excluding fuels for international marine bunkers. Industrial process emissions - the only category of anthropogenic emissions not directly linked to energy consumption - are also not examined here because of a lack of consistent and reliable historical statistics. Sources of such emissions include oil refineries, coke plants, sinter plants, pig iron blast furnaces, non-ferrous metal smelters, sulphuric acid plants, nitric acid plants, cement and lime plants and pulp mills; in 2005 they contributed about $7 \%$ and $5 \%$ to total European $\mathrm{SO}_{2}$ and $\mathrm{NO}_{\mathrm{x}}$ emissions, respectively (EMEP 2009). The share of $\mathrm{CO}_{2}$ process emissions in Europe, including gas flaring, was about $5 \%$ of total emissions in 2005 (UNFCCC 2009).

Table 1 Sector/fuel combinations applied for emission calculations for $\mathrm{SO}_{2}$ and $\mathrm{NO}_{\mathrm{x}}$

\begin{tabular}{ll}
\hline Sectors & Fuels \\
\hline Power and heat production & Hard coal \\
Industry & Lignite \\
& Coke \\
Households and services & Biomass and waste \\
& Gasoline \\
Transport and aviation & Diesel \\
& Heavy fuel oil \\
Energy conversion & Natural gas and derived gases \\
& Others (renewables, nuclear, electricity, heat)
\end{tabular}




\section{Results}

\subsection{Emissions in Europe 1960-2010}

In WEU, the volume of economic activity increased steadily by about $2.2 \%$ /year between 1960 and 2010, resulting in a quadrupling of GDP (real-term, PPP-adjusted). In the early years of this period, emissions of $\mathrm{SO}_{2}, \mathrm{NO}_{\mathrm{x}}$ and $\mathrm{CO}_{2}$ developed in parallel to the level of economic activity (Fig. 2). However, $\mathrm{SO}_{2}$ and $\mathrm{NO}_{\mathrm{x}}$ emissions later exhibited a distinct
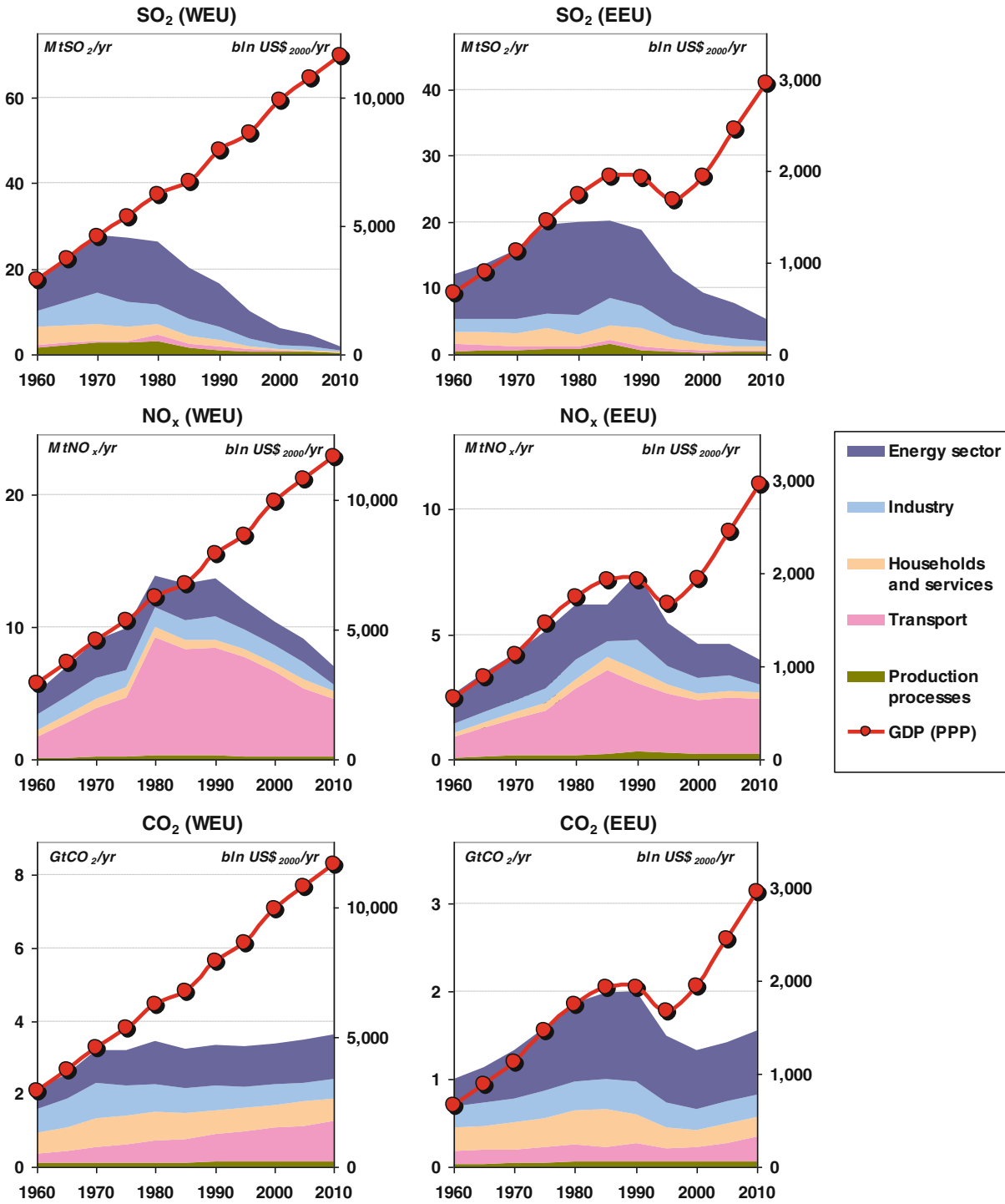

Fig. 2 Evolution of GDP (PPP) and emissions of $\mathrm{SO}_{2}, \mathrm{NO}_{x}$, and $\mathrm{CO}_{2}$ by sector in Western Europe (WEU) and Eastern Europe (EEU) between 1960 and 2010; adopted from databases of the RAINS and GAINS models (Amann 1990; Amann et al. 2008; EMEP 2009; IEA 2010) 
decoupling from GDP, coinciding with a time when public concerns about their negative environmental impacts (i.e., about 'acid rain' and 'ground-level ozone') emerged. After peaking in the 1970s, $\mathrm{SO}_{2}$ emissions declined by $90 \%$ through 2010 ; similarly, $\mathrm{NO}_{\mathrm{x}}$ emissions declined by $50 \%$ after a maximum in the 1980s (Schöpp et al. 2003). For $\mathrm{CO}_{2}$, such a pronounced decoupling effect has not yet been observed.

In EEU, political changes in the 1990s were accompanied by drastic structural changes in national economies. This led to temporary stagnation and a drop in GDP, and to significant alterations in energy systems. From Fig. 2 it is clear that the contributions of individual emission sources are comparable in the WEU and EEU regions; however, the decline in emissions was delayed by about 10 years in EEU compared with WEU. In addition to economic and structural transitions, the implementation of new environmental legislation in EEU contributed substantially to the rapid decrease in emission burden.

Figure 3 shows the share contributed by solid, liquid and gaseous fuels to overall emission levels. While the combustion of coal is the major source of sulphur emissions, oil products used in the transport sector dominate $\mathrm{NO}_{\mathrm{x}}$ emission profiles in both the WEU and EEU regions. The increasingly higher share of natural gas in the fuel mix is responsible for its growing contribution to total $\mathrm{CO}_{2}$ emissions.

\subsection{Key factors driving pollutant emissions}

\subsubsection{Population and income}

During the period of interest, population grew at an annual rate of $0.4 \%$ in WEU and $0.6 \%$ in EEU. Whereas a pattern of gradual continued growth was observed in the former, population stabilised and even began to decline during the early 1990s in the latter (Fig. 4). Over the same timeframe, average income more than tripled in WEU and more than doubled in EEU. Even with all other factors held constant, pollutant emissions would be expected to significantly increase as a consequence of observed increases in income.

The EKC hypothesis suggests that, on a per capita basis, emissions will display an inverse $\mathrm{U}$-shaped function with respect to income. Figure 5 shows the trajectories of emissions of $\mathrm{SO}_{2}, \mathrm{NO}_{\mathrm{x}}$ and $\mathrm{CO}_{2}$ plotted against income levels for WEU and EEU countries, respectively. In principle, the EKC hypothesis is consistent with $\mathrm{SO}_{2}$ emissions in WEU, which increase up to $\sim 13,000 \mathrm{US}-\$ / \mathrm{yr}$, then decline monotonically with increasing income. For EEU, per capita emissions peaked at an income of $\sim 7,000 \mathrm{US}-\$ / y r$, and declined much more rapidly than in WEU. For instance, per capita emissions of about $20 \mathrm{~kg} \mathrm{SO} /$ year were reached in EEU at an income of about 12,000 US-\$/yr, while in WEU the same emission level was achieved at about 24,000 US-\$/yr. Similar trends apply for $\mathrm{NO}_{\mathrm{x}}$, where emissions in both regions peaked at comparable intensities, but significantly different income levels. Furthermore, the peaks of $\mathrm{SO}_{2}$ and $\mathrm{NO}_{\mathrm{x}}$ emissions coincide for EEU with respect both to time and per capita income, while they are rather different within WEU. For $\mathrm{CO}_{2}$ emissions, there is no significant income dependency in WEU, while the post-1990 economic restructuring in EEU appears to have set per capita emissions on a new growth path - although at a lower absolute level. In general, all curves for EEU show a distinct break in 1990 at the onset of economic restructuring.

From a broader perspective, data for EEU through 1990 combined with the full range of data for WEU provide only limited support for the existence of universal U-shaped relationships between emissions and per capita income in the ranges considered here. Such relationships are evidently region- and pollutant-specific, peaking at different income levels, and do not indicate a significant decline in $\mathrm{CO}_{2}$ emissions with increasing prosperity. 

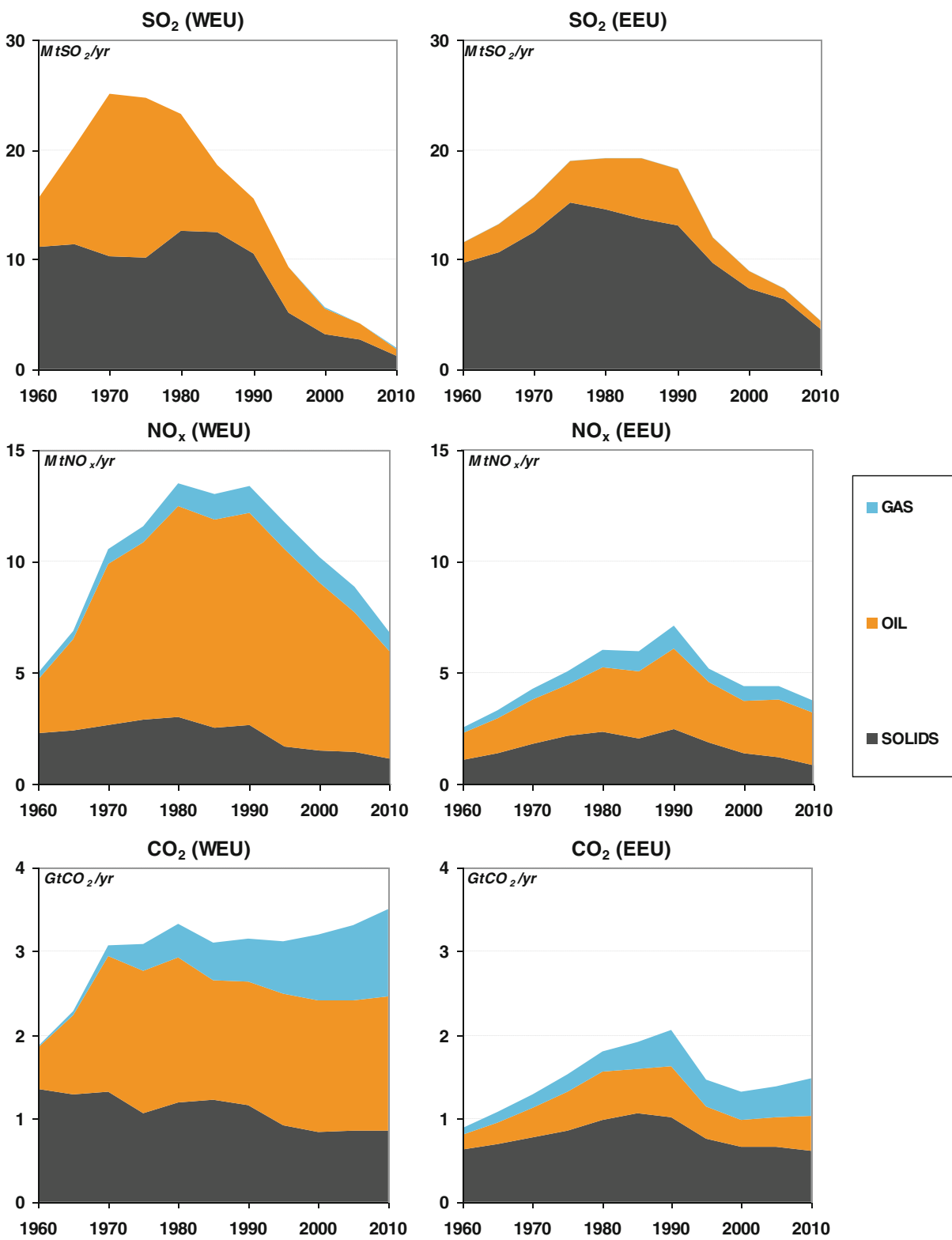

Fig. 3 Evolution of emissions for gas, oil and solid fuels in Western Europe (WEU) and Eastern Europe (EEU) between 1960 and 2010; adopted from databases of the RAINS and GAINS models (Amann 1990; Amann et al. 2008; EMEP 2009; IEA 2010)

However, developments in Eastern Europe after 1990 clearly signal a departure from the status quo, indicating the potential importance of structural changes in emission trends. In sum, historic evidence for $\mathrm{SO}_{2}, \mathrm{NO}_{\mathrm{x}}$ and $\mathrm{CO}_{2}$ emissions in Western and Eastern Europe suggests some income dependency that might be in line with the EKC hypothesis, but this is hardly definitive; in the following sections, we explore alternative factors that could explain the observed changes in pollutants over time. 

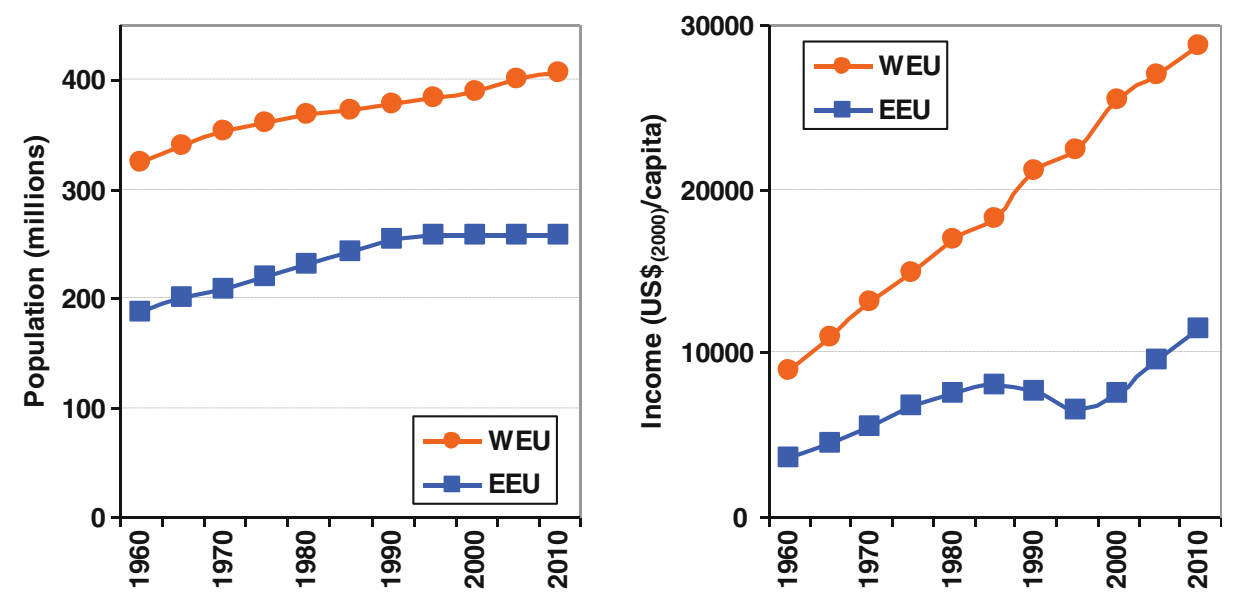

Fig. 4 Evolution of overall population and GDP per capita in Western Europe (WEU) and Eastern Europe (EEU), 1960-2010. Adopted from RAINS (Amann 1990) and IEA (2009a, b)

\subsubsection{Energy intensity}

Energy intensity, expressed as energy use per unit of GDP produced, has evolved quite differently in WEU and EEU. In the former, after a period of growth, energy intensity

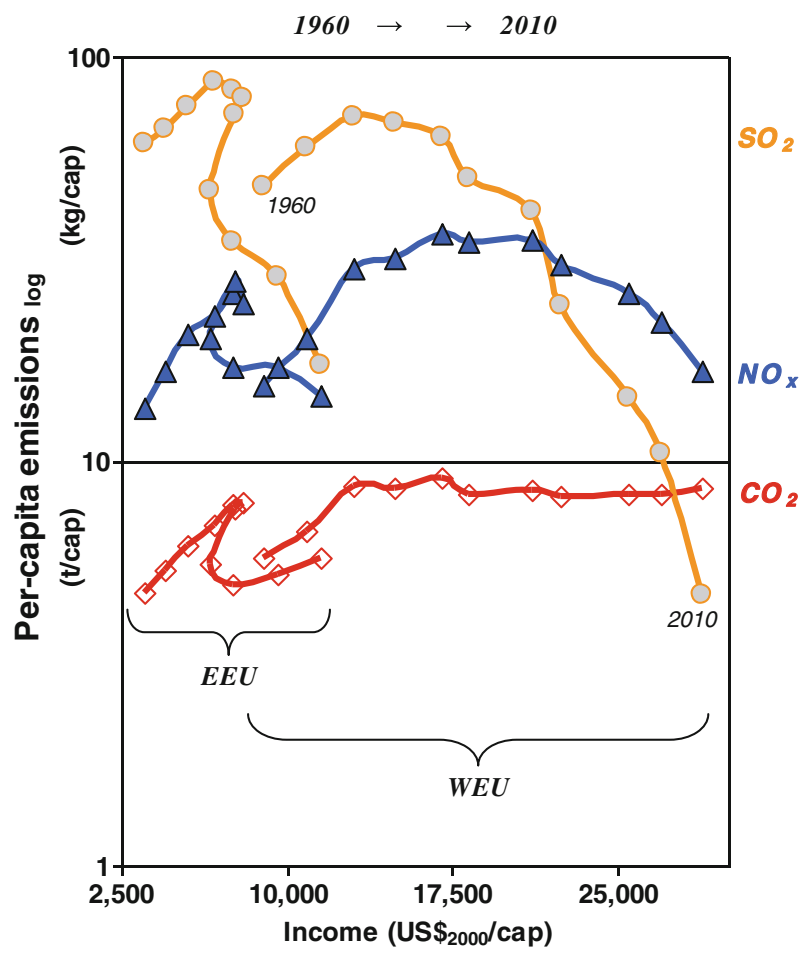

Fig. 5 Trajectories of emissions per capita versus per capita income from 1960-2010 in Western Europe (WEU) and Eastern Europe (EEU). Adopted from RAINS (Amann 1990) and IEA (2009a, b) 
gradually decreased, such that present levels are nearly $30 \%$ lower than in 1970 (Fig. 6- Left panel, lower lines), while energy consumption per capita increased steadily (Fig. 6 - Left panel, upper lines). In some WEU countries, oil price shocks affected the level and structure of energy consumption in the mid-1970s and early 1980s. In many WEU countries, energy growth slowed around 1990. Some of these economies managed to decouple energy growth from economic growth. In contrast, energy intensity remained stable or even increased in the EEU region through the 1990s. The strong decline after 1990 is due to the recession in Central and Eastern European countries that underwent a process of economic transition to a market economy. In EEU, energy consumption per capita dropped sharply at the 1990 recession, but increased steadily both before and after.

As explained in Section 3.1, changes in overall energy intensity according to our definition also encompass the contribution of improved conversion efficiency and energy saving measures. Investments in energy conservation during the period of interest were primarily motivated by the pressure of increasing energy prices, on both the supply and demand sides of the energy system. The trajectories of real energy prices (adjusted for inflation) since 1970 (Fig. 6 - Right panel) in WEU evidence very strong fluctuations, however, an increasing trend is observed, especially for oil (gas and oil prices have usually been linked in international markets). The price of coal also increased after the 1970s, though changes have been not as dramatic as for oil and gas. The observed trends suggest a significant correlation between growth in energy costs and reductions in energy intensity. Moreover, the price of energy is one of the decisive components for fuel choice, as discussed in the next paragraph.
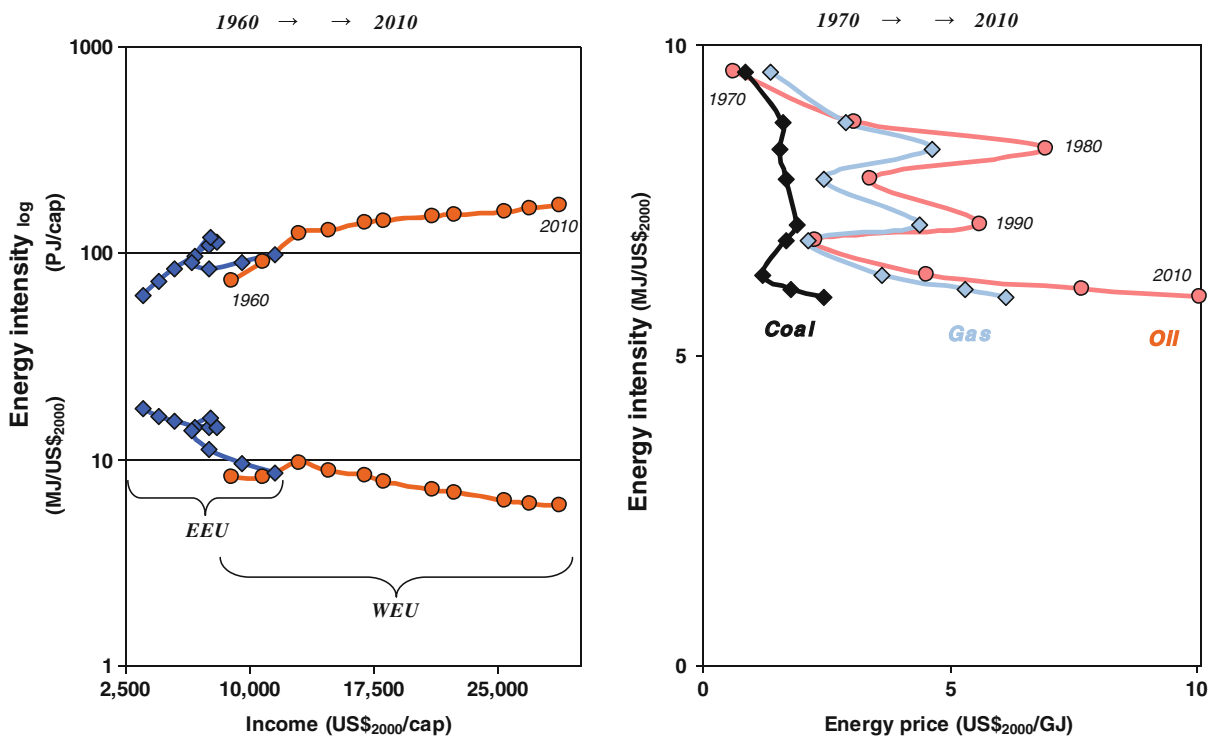

Fig. 6 Left panel - trajectories of energy intensity (ENE/GDP) with respect to economic output (lower lines) and per capita energy consumption (upper lines) in Western Europe (WEU) and Eastern Europe (EEU), 19602010. Adopted from RAINS (Amann 1990) and IEA (2009a, b). Right panel-evolution of energy intensity (ENE/GDP) in relation to real fuel prices in WEU, 1970-2010. Adopted from BP (2012) and World Bank (2013) 


\subsubsection{Fuel mix}

An important factor driving changes in emissions is the fuel structure of the energy system. Fuel switches have occurred on the supply side since the 1970s, e.g., in the power sector, in the form of expanding nuclear generation capacity, growth in renewables and natural gas use. On the demand side, there has been a shift toward more electricity and heat consumption instead of direct fuel combustion. Figure 7 illustrates the evolution of the overall fuel mix from 1960 to 2010. The share of non-fossil fuels in WEU approached $25 \%$ by 2010 , increasing by a factor of six relative to the base year. Similar steep increases are reported for natural gas, which experienced sevenfold growth. The relative importance of coal decreased, while oil usage shifted from heat and power production toward transportation. The transition toward natural gas, nuclear and renewable energies was substantially slower in EEU. Moreover, consumption of coal and oil products increased until 1995 in EEU, making the fuel substitution effect less pronounced in comparison to that in WEU.

\subsubsection{Emission intensity}

It is clear that ongoing economic and energy sector changes during the period examined had an impact on emission intensity (i.e., the amount of air pollutants released per unit of energy consumed). Of these, the structural changes initiated after the oil price shocks-especially the second shock in 1979 (Kohl 1982) - and during the post-1990 transition period in Central and Eastern Europe are most significant. In addition, changes in emission intensities reflect transitions in the composition of particular economic sectors; for instance, shifts from manufacturing to services, changes in the ratio between passenger and freight transport or improvements in conversion efficiency.

Figure 8 shows trajectories of emission intensity in relation to change in the non-fossil fraction of the overall fuel mix. For both WEU and EEU, emission intensity for $\mathrm{SO}_{2}$ and $\mathrm{NO}_{\mathrm{x}}$ decreased with growing share of carbon-neutral fuels, though this trend for $\mathrm{NO}_{\mathrm{x}}$ is only observed after 1980, due to changes in the transport fuel mix. The overall impacts of fuel
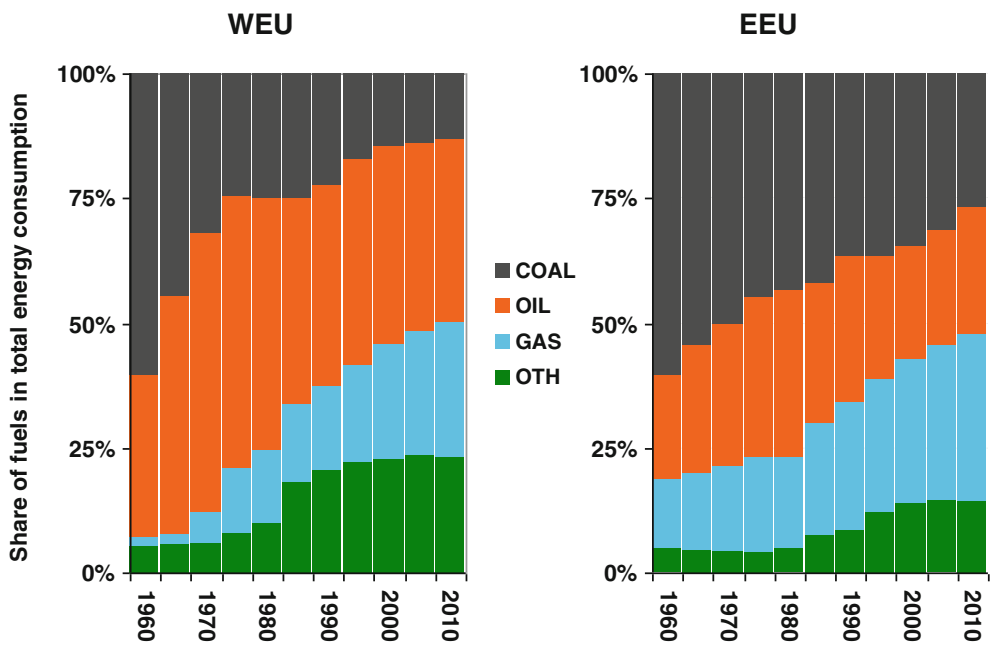

Fig. 7 Evolution of fuel choices in Western Europe (WEU) and Eastern Europe (EEU), 1960-2010. Adopted from RAINS (Amann 1990) and IEA (2009a, b) 

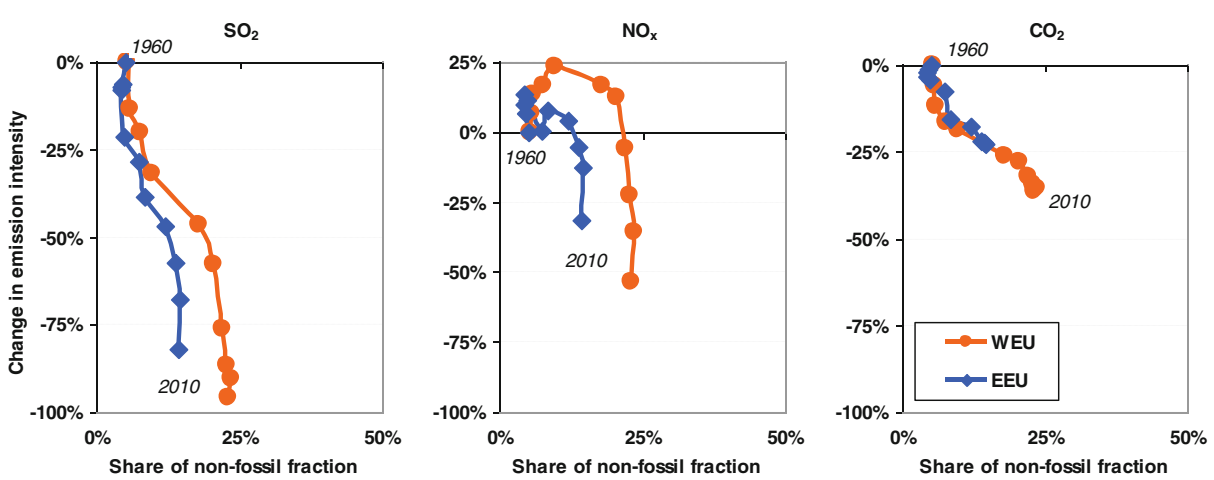

Fig. 8 Evolution of emission intensity for $\mathrm{SO}_{2}, \mathrm{NO}_{\mathrm{x}}$ and $\mathrm{CO}_{2}$ emissions in Western Europe (WEU) and Eastern Europe (EEU) relative to 1960 as a function of the share of non-fossil energy fraction. Adopted from RAINS (Amann 1990) and IEA (2009a, b)

mix changes on $\mathrm{SO}_{2}$ and $\mathrm{NO}_{\mathrm{x}}$ emission intensity reductions are complex, since, over the last two decades, the continuous use of fossil fuels has been accompanied by the adoption of targeted emission control measures and improved fuel quality. For $\mathrm{CO}_{2}$ emissions, however, changes in fuel mix represent a major mitigation component in the absence of direct end-ofpipe abatement measures. This explains the proportional reduction in aggregated $\mathrm{CO}_{2}$ emission intensity following the growth in non-fossil fuels.

\subsection{Summary of factors leading to emission changes over time}

\subsubsection{Sulfur dioxide}

The decomposition approach discussed in Section 3.1 allows for quantification of emission reductions attributable to particular technological, behavioural or policy-related elements. A simple approach to interpreting these results it to examine how the three main drivers described above (i.e., improved energy intensity, improved fuel mix and end-of-pipe measures) have factored into reductions in emissions over the study period. Figure 9 shows total observed $\mathrm{SO}_{2}$ emissions in the WEU and EEU regions between 1960 and 2005, projected through 2010. The dark area ("Actual emissions") illustrates the empirical evolution of $\mathrm{SO}_{2}$ emissions. The red line at the upper margin shows the hypothetical emissions that would have occurred in the absence of any mitigation component; i.e., it represents growth in emissions with growing GDP. Intermediate between these boundaries, different colours represent the contribution of the three drivers to emission reductions: changes in energy intensity and efficiency (blue), changes in energy structure/fuel mix (green), and control measures (yellow).

In WEU, $\mathrm{SO}_{2}$ emissions have declined monotonically since 1970. Changes in fuel mix combined with reduced energy intensity have offset continued growth in energy consumption, while control measures have further decreased emissions. As of 2010, the reductions in $\mathrm{SO}_{2}$ emissions attributable to control measures and to energy intensity improvements are of similar moderate magnitude, while fuel mix changes have become the most important abatement element. In EEU, an increase in energy intensity (striped) outweighed the effects of fuel switching and better fuel quality during the first half of the study period, resulting in moderate emission growth through the mid-1980s. After 1990, a decline in total energy consumption brought emissions down, and this process accelerated via efficiency 


\section{WEU}

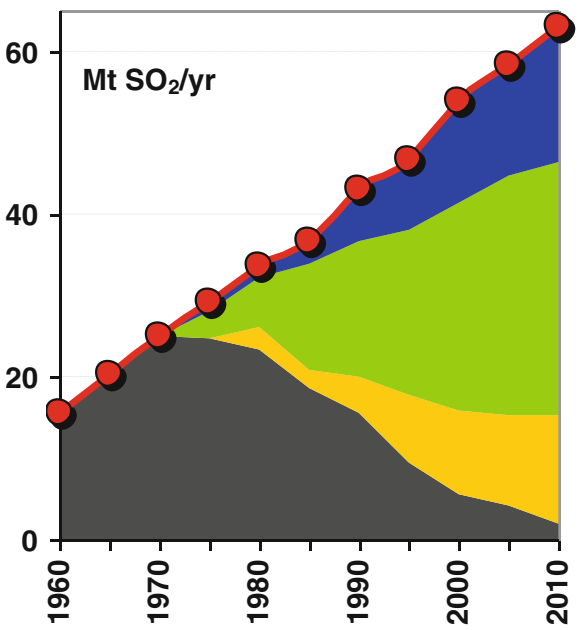

Increased through worsening of energy intensity

Avoided through energy intensity improvement of GDP

\section{Avoided through changes in fuel mix}

\section{EEU}

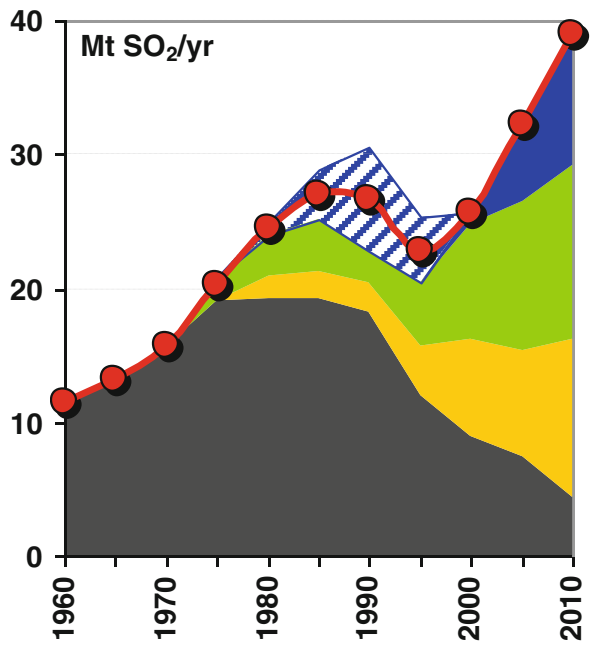

Avoided through end-of-pipe measures

\section{Actual emissions}

Hypothetical uncontrolled emissions for constant energy intensity and fuel mix

Fig. 9 Determinants of reductions in $\mathrm{SO}_{2}$ emissions in Western Europe (WEU) and Eastern Europe (EEU), $1960-2010$

improvements, coal substitution with natural gas and the adoption of pollution control legislation in most EEU countries.

It is important to note that the systematic adoption of end-of-pipe measures to reduce emissions (e.g., FGDs) did not take place before 1985. Nevertheless, modification of the characteristics of fuels used in a range of combustion processes led to changes in the average emission factor for several sectors. Some changes in fuel quality, e.g., sulphur content in coal, were autonomous, while others were enforced by legislation-for example, the sulphur content standards for transport or domestic liquid fuels (UN-ECE 1987). The evolution of the aggregated sector-specific emission factors for $\mathrm{SO}_{2}$ in WEU and EEU is summarised in Table 2. To understand the relative impact of the areas in Fig. 9, it is necessary to examine the data at the country level, as in Section 4.4 below.

\subsubsection{Nitrogen oxides}

Growth in $\mathrm{NO}_{\mathrm{x}}$ emissions differed from growth in $\mathrm{SO}_{2}$ emissions for both regions. While $\mathrm{SO}_{2}$ in WEU declined by some $40 \%$ between 1970 and 1990, $\mathrm{NO}_{\mathrm{x}}$ increased by $27 \%$ during the same period (Fig. 10). In EEU, the corresponding increase in $\mathrm{NO}_{\mathrm{x}}$ was over $65 \%$. This increase is largely a product of the growth in energy consumption, but, in contrast to $\mathrm{SO}_{2}$, it is generated not only from stationary emission sources but also from transport. After 
Table 2 Evolution of average emission factors by sector and the share of diesel in transport fuels in Western Europe (WEU) and Eastern Europe (EEU), 1960-2010. Adopted from RAINS (Amann 1990), IEA (2009a) and IEA (2009b)

\begin{tabular}{|c|c|c|c|c|c|c|c|c|}
\hline & Region & Sector & 1960 & 1970 & 1980 & 1990 & 2000 & 2010 \\
\hline \multirow{8}{*}{$\begin{array}{l}\text { Average emission factor for } \\
\text { sulfur dioxide }\left(\mathrm{gSO}_{2} / \mathrm{MJ}\right)\end{array}$} & \multirow[t]{4}{*}{ WEU } & Energy & 0.94 & 1.07 & 0.78 & 0.43 & 0.14 & 0.04 \\
\hline & & Industry & 0.55 & 0.63 & 0.40 & 0.28 & 0.10 & 0.03 \\
\hline & & Domestic & 0.58 & 0.31 & 0.17 & 0.11 & 0.03 & 0.01 \\
\hline & & Transport & 0.19 & 0.19 & 0.08 & 0.08 & 0.02 & 0.01 \\
\hline & \multirow[t]{4}{*}{ EEU } & Energy & 1.73 & 1.47 & 1.18 & 0.74 & 0.56 & 0.25 \\
\hline & & Industry & 0.46 & 0.36 & 0.36 & 0.38 & 0.31 & 0.16 \\
\hline & & Domestic & 0.48 & 0.43 & 0.37 & 0.24 & 0.15 & 0.08 \\
\hline & & Transport & 0.55 & 0.24 & 0.23 & 0.16 & 0.16 & 0.05 \\
\hline \multirow{8}{*}{$\begin{array}{l}\text { Average emission factor for } \\
\text { nitrogen oxides }\left(\mathrm{gNO}_{\mathrm{x}} / \mathrm{MJ}\right)\end{array}$} & \multirow[t]{4}{*}{ WEU } & Energy & 0.23 & 0.22 & 0.12 & 0.12 & 0.07 & 0.05 \\
\hline & & Industry & 0.16 & 0.13 & 0.13 & 0.17 & 0.13 & 0.04 \\
\hline & & Domestic & 0.07 & 0.06 & 0.05 & 0.04 & 0.04 & 0.03 \\
\hline & & Transport & 0.49 & 0.63 & 1.06 & 0.73 & 0.48 & 0.27 \\
\hline & \multirow[t]{4}{*}{ EEU } & Energy & 0.30 & 0.27 & 0.19 & 0.17 & 0.12 & 0.08 \\
\hline & & Industry & 0.09 & 0.09 & 0.10 & 0.14 & 0.13 & 0.06 \\
\hline & & Domestic & 0.04 & 0.05 & 0.05 & 0.07 & 0.05 & 0.04 \\
\hline & & Transport & 0.43 & 0.67 & 0.98 & 0.92 & 0.88 & 0.55 \\
\hline \multirow[t]{2}{*}{ Share of diesel fuel } & WEU & Transport & $23 \%$ & $29 \%$ & $32 \%$ & $37 \%$ & $44 \%$ & $55 \%$ \\
\hline & EEU & Transport & $32 \%$ & $34 \%$ & $38 \%$ & $40 \%$ & $46 \%$ & $54 \%$ \\
\hline
\end{tabular}

1985, control measures were phased in, gradually reducing emissions (Table 2). Structural change seems to have played only a minor role.

The analysis of changes in $\mathrm{NO}_{\mathrm{x}}$ emissions is more difficult than for $\mathrm{SO}_{2}$. Different factors tend to overlap and the same factors change the way they impact emissions over time. Also, the choice of reference year is very important. While structural change reduced emissions growth up to 1990, it increased emissions - or more precisely, diminished the impact of control measures - for the period after 1990. This trend was more pronounced in the EEU region (striped area).

Development in the transport sector is key to understanding the causes of $\mathrm{NO}_{\mathrm{x}}$ emission trends. Both petrol and diesel consumption in the transport sector grew significantly over the period examined, however, the share of diesel in transportation fuels increased at a similar rate (Table 2). Between 1970 and 1990, the structural shift towards diesel was as important a factor in increasing $\mathrm{NO}_{\mathrm{x}}$ emissions as the growth in transport, and from 1990 to 2000, when energy consumption declined, this factor significantly counteracted the reduction in emissions. While structural changes in the transport sector tend to increase emissions, structural changes for stationary sources tend to reduce emissions, as for $\mathrm{SO}_{2}$. This also explains why the overall net effect of fuel mix change is rather small. It is also noted that initial emission regulations for automobiles within the EU were already specified by 1970 (EC 1970). Thereafter, European emission standards (Euro) for light and heavy duty vehicles were defined in a series of directives, whereas the first standards for passenger vehicles came into force in 1992, and the most recent standards (Euro5/V) have been required since 2009/2010 (EC 2007). 


\section{WEU}

30

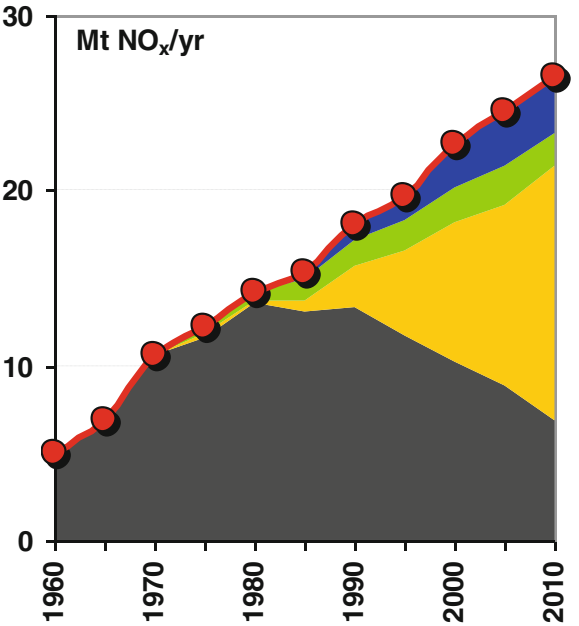

$\angle-3$ Increased through worsening of energy intensity and fuel mix

\section{Avoided through energy intensity improvement of GDP}

Avoided through changes in fuel mix
EEU

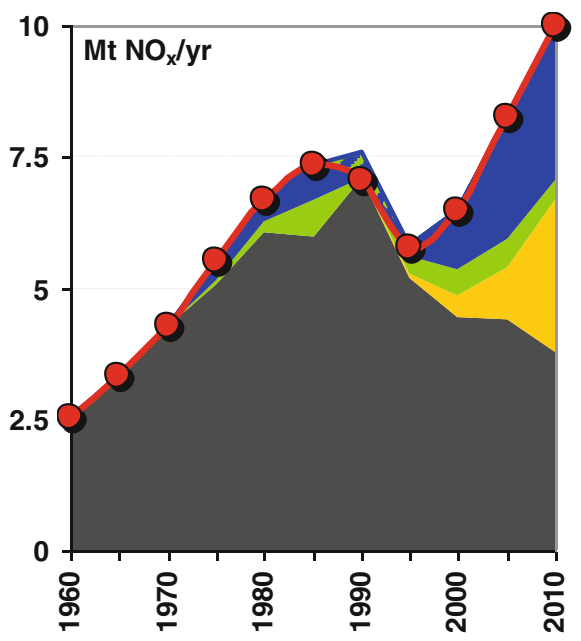

Avoided through end-of-pipe measures

\section{Actual emissions}

- Hypothetical uncontrolled emissions for constant energy intensity and fuel mix

Fig. 10 Determinants of reductions in $\mathrm{NO}_{\mathrm{x}}$ emissions in Western Europe (WEU) and Eastern Europe (EEU), $1960-2010$

Another important process that plays a role in $\mathrm{NO}_{\mathrm{x}}$ emissions is a transition across modes and categories within the transport sector. Examples include: the shift from two stroke to four stroke engines, the changing share of two-wheelers in passenger transport, the replacement of heavy duty trucks by light duty vehicles, and the ratio between fuel use in freight transport and in cars. These changes are not analyzed in detail in this study, but are reflected in aggregate in the structural emission drivers. Figure 10 also shows that control measures are the most important factor driving $\mathrm{NO}_{\mathrm{x}}$ emission reductions - more than $75 \%$ of effective measures through 2010 involved the transport sector. In the 1990s, pollution control measures affecting petrol-fuelled cars, e.g., catalytic converters, contributed most to reductions in WEU, but the contribution from equivalent measures for diesel-powered vehicles is expected to reach similar levels in 2010 and beyond (Amann et al. 2008; Borken-Kleefeld and Ntziachristos 2012).

\subsubsection{Carbon dioxide}

$\mathrm{CO}_{2}$ emissions from fossil fuel combustion have rapidly increased in WEU, by $60 \%$ from 1960 to 1970 (Fig. 11). The energy crisis in the 1970s followed by the oil glut resulted in temporary demand reductions in the middle of the 1980s (Salameh 2004). Changes in 


\section{WEU}

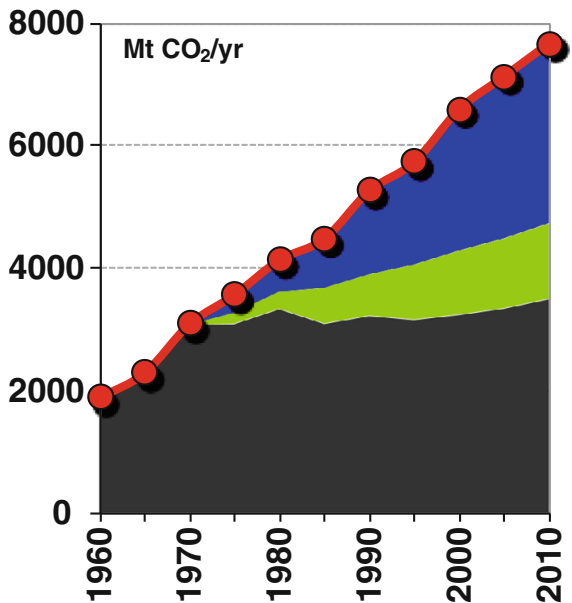

EEU

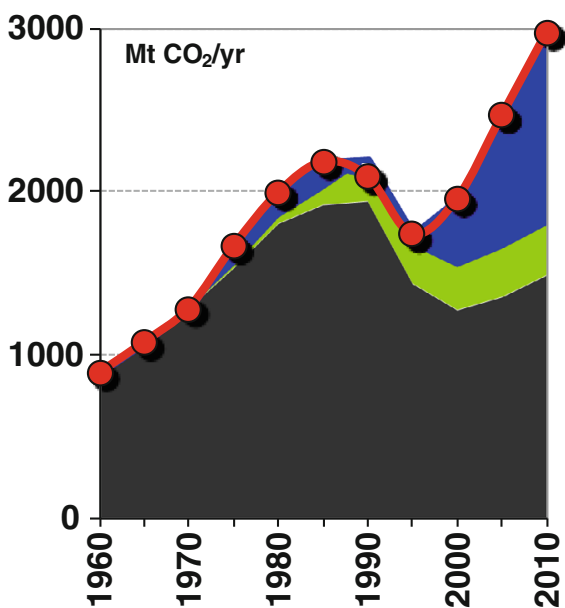

$-\infty$ Increased through worsening of energy intensity

- Avoided through energy intensity

\section{Avoided through changes in fuel mix}

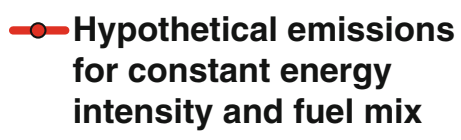

Fig. 11 Determinants of reductions in $\mathrm{CO}_{2}$ emissions in Western Europe (WEU) and Eastern Europe (EEU), $1960-2010$

economic structure, improved energy productivity, and energy-saving measures constitute the main sources of reductions in $\mathrm{CO}_{2}$ emissions over the study period. High oil prices reinforced the introduction of alternative and less carbon-intensive fuels into energy markets (Figs. 6 and 7); through the early 1990s, fuel switching had similar impact on reductions in $\mathrm{CO}_{2}$ emissions as the drop in energy intensity. By 2010, changes in fuel mix contributed around $30 \%$ to overall $\mathrm{CO}_{2}$ reductions, whereas improvements in energy intensity played a larger role.

In EEU, $\mathrm{CO}_{2}$ emissions grew by $2.1 \%$ per year up through 1990 , in tandem with the growth of the economy (Fig. 11). Inefficient use of fossil fuels offset the $\mathrm{CO}_{2}$-reducing effect of the growing nuclear and hydropower supply capacities experienced during this period (Fig. 7). The transition of EEU countries toward market-oriented economies resulted in the attenuated market distortion of fuel prices, and simultaneously in a rapid drop in energy use consequent to the conversion of the industrial sector. The recent economic recovery is associated with an increase in $\mathrm{CO}_{2}$ emissions over the last decade.

\subsection{Country results}

Decomposition analysis for individual countries is of great value for gaining detailed insights about the performance and interplay of driving forces for pollution reductions. We present results for the United Kingdom and Poland to highlight a few of the most significant features. Additional components of emission reductions beyond those considered in Figs. 9, 10 and 11 are explicitly accounted for here. These components include growth in the power generation sector, evolution of transport activities, and the contribution of diesel fuel to the $\mathrm{NO}_{\mathrm{x}}$ emission profile. Impacts on emissions resulting from improvements in energy 

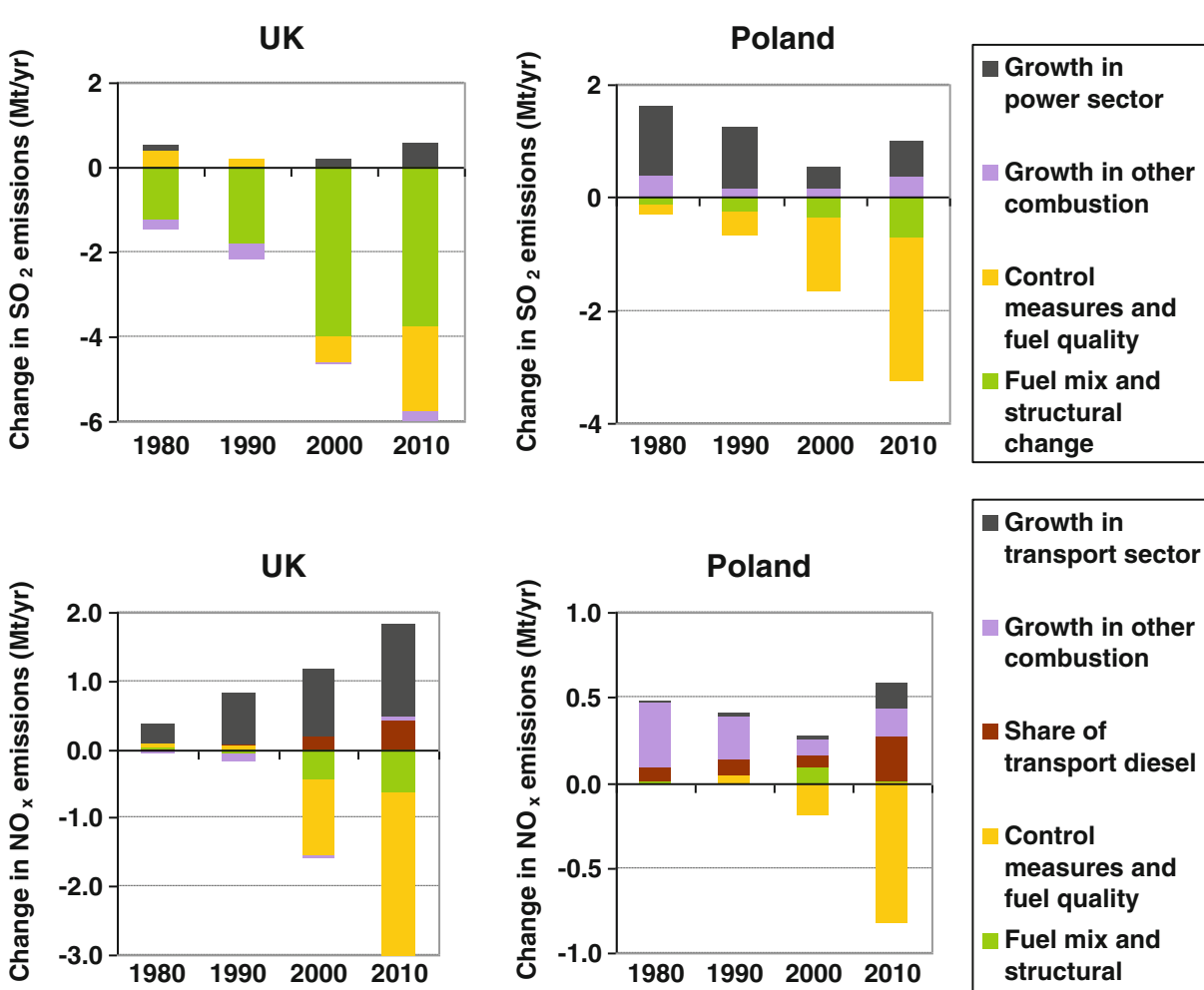

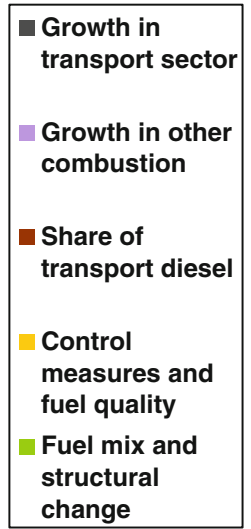
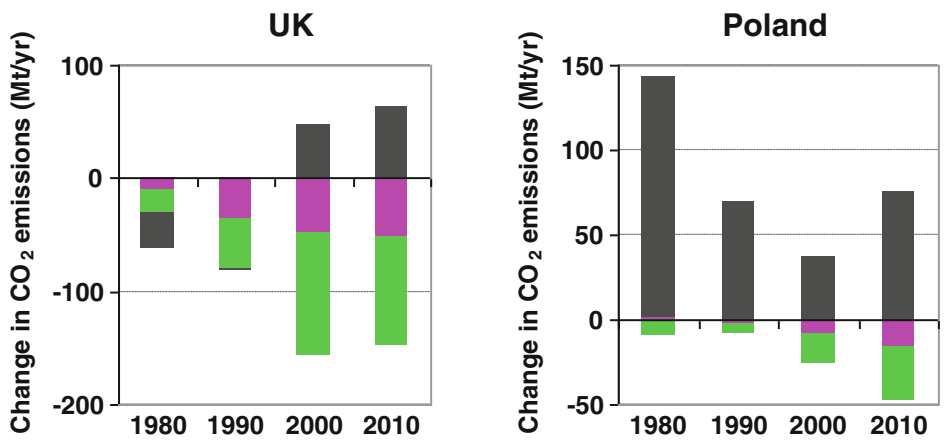
Growth in fossil fuel combustion
Increase in non- fossil fraction
Inter-fossil fuel switch

Fig. 12 Determinants of $\mathrm{SO}_{2}, \mathrm{NO}_{\mathrm{x}}$ and $\mathrm{CO}_{2}$ emission reductions compared to 1970 in the United Kingdom and Poland

intensity and fuel mix are aggregated within one term ("Fuel mix and structural change"). Driving factors are decomposed relative to the year 1970, since their impact is obvious only after this point.

The United Kingdom reduced its emissions substantially during the 1990s through restructuring of the energy system, in particular by decreasing coal combustion in the power plant sector. A large fraction of coal power generation has been substituted by natural gas power plants, but nuclear power, too, and more recently renewable energy, figure increasingly in the fuel mix. Structural changes in the energy system thus played a dominant role in reductions of $\mathrm{SO}_{2}$ and $\mathrm{CO}_{2}$ emissions. End-of-pipe measures became important in $\mathrm{SO}_{2}$ 
emission reductions only toward the end of the study period, as the United Kingdom started to install control equipment only after 1990 or even 1995 (UN-ECE 1995).

As was apparent at the regional level (see Section 4.3.2), the effect which overall structural change in the $\mathrm{UK}$ has on $\mathrm{NO}_{\mathrm{x}}$ emissions changes with the relative importance of two opposing forces: fuel switching for stationary sources tends to reduce emissions, whereas relative growth of the transport sector increases emissions. The rising share of diesel cars in the UK nearly offsets the reductions achieved through the modified fuel mix in nontransport sectors. On the other hand, the analysis reveals a very high efficiency of control measures dedicated to $\mathrm{NO}_{\mathrm{x}}$ abatement.

In Poland, as in most EEU countries, the tendency for emissions to grow dominated until the 1990s, whereas in later decades emissions decreased as a result of drops in energy demand and the adoption of emission control measures. In spite of growing shares of natural gas, biomass and other renewables, the Polish energy system continues to rely on coal combustion. Therefore, the effect of fuel mix changes towards $\mathrm{SO}_{2}$ and $\mathrm{CO}_{2}$ reductions is much lower than in the UK (Fig. 12). However, in combination with efficiency gains, fuel switching does help to moderate the growth in emissions that is the projected result of economic recovery. Add-on desulphurization technologies, gradually implemented after economic changes in the 1990s and due to EU-accession requirements in the 2000s, have been the main driver for the remarkable $\mathrm{SO}_{2}$ reductions achieved. The decrease in average $\mathrm{SO}_{2}$ emissions prior to the 1990 s was linked with changing fuel quality and with a coal-tolignite substitution in the power generation sector (Cofala and Bojarski 1987).

Evolution of $\mathrm{NO}_{\mathrm{x}}$ emissions in Poland is again dominated by solid fuel combustion in power plants. Only after 2000 did growth in transport demand and a greater share of diesel vehicles outweigh the contribution from stationary sources. Similar to the $\mathrm{UK}, \mathrm{NO}_{\mathrm{x}}$-controls enforced though environmental legislation have brought emissions below 1970 levels.

Individual country analyses indicate that differences among countries tend to diminish with time. While in the first half of the study period many country-specific features were evident, by 2010 , the patterns have become rather similar. This may reflect the impact of international legislation regarding air pollutants, including both the Gothenburg Protocol (UN-ECE 1999) and EU legislation (EC 2001), as well as broad international climate agreements including the Kyoto Protocol (UNFCCC 1997). Continuous enforcement of environmental policies will eventually diminish the differences between countries with respect to the relative importance of structural changes compared to targeted abatement measures, as countries converge to the European average in the medium term. The overall effectiveness of control measures may vary with local circumstances. One clearly important factor is how early measures are introduced. The rate of implementation of controls may still differ slightly from country to country in the coming years, yet emissions should converge toward the European average and variability is expected to be much lower than before 2000 .

\section{Discussion}

Our decomposition exercise proves that many emission reductions are not the result of specific control measures. Rather than resulting from targeted abatement efforts, they are shown to be the consequence of variation in energy structure, overall economic changes or technological advances. ${ }^{4}$ These changes are autonomous of emission reduction objectives

\footnotetext{
${ }^{4}$ For the further discussion on the role of technological progress behind emission reductions and the effectiveness of international environmental treaties see, e.g., Barrett et al. (2006) and Dekker et al. (2012).
} 
and are mainly a consequence of economic developments. The analysis of the observed emission reductions allows some conclusions about the substantial importance of dedicated environmental legislation and international policy efforts, such as the protocols under CLRTAP (UN-ECE 1985, 1999). Nevertheless, even countries that did not become party to the protocols and thus were not ready to support their environmental objectives have reduced emissions as a consequence of autonomous changes in the economy. Moreover, some countries that became protocol parties have reduced emissions beyond the levels required (CIAM 2007).

The analysis shows that changes in energy structure (including technological advances and other changes within sectors) are likely more important in reducing emissions for $\mathrm{SO}_{2}$ than for $\mathrm{NO}_{\mathrm{x}}$. Without such changes, overall European emissions would not decrease below 1960 levels, as is now expected. For $\mathrm{NO}_{\mathrm{x}}$, structural change tends to act in the opposite direction, and on the whole is much less important. This difference supports the conclusion that for $\mathrm{NO}_{\mathrm{x}}$, there is the potential for structural change to further reduce emissions, potentially at lower cost, than is anticipated at present. It is possible, too, to imagine a dramatic shift away from the emission-intensive vehicle technology presently used for transport, similar to what has been observed in the power plant sector. Thus far, structural change and, in particular, the growth of transport, have reduced the effectiveness of measures to control $\mathrm{NO}_{\mathrm{x}}$. The extent of this effect explains some of the differences in overall emission reductions between countries. Also, the differences between countries with respect to the impact of structural change on $\mathrm{SO}_{2}$ emissions were important during the 1990 s, but, according to forecasts, such differences tend to diminish with time.

There is an obvious link between the adoption of the first sulphur Protocol in 1985 (UNECE 1985) and the timing of the introduction of controls on sulphur emissions. Among WEU countries, the United Kingdom neither joined the first sulphur Protocol nor introduced abatement measures at that time. It did, however, phase in control measures upon the adoption of the second sulphur Protocol in 1994 (UN-ECE 1994), to which it became a Party. Such an obvious link cannot be made for Central and Eastern European countries. Similarly, the adoption of the $\mathrm{NO}_{\mathrm{x}}$ Protocol in 1988 (UN-ECE 1988) can be linked to the timing of the introduction of control measures. Finally, it is obvious that the adoption of the 1999 Gothenburg Protocol (UN-ECE 1999), which addresses not only $\mathrm{SO}_{2}$ and $\mathrm{NO}_{\mathrm{x}}$, but also VOCs and ammonia, was followed by a broader application of emission control measures - in particular as it was signed by more countries than any previous Protocol (CIAM 2007).

This analysis strongly indicates that international environmental cooperation, as conducted within the framework of the CLRTAP, has had significant effects. Control measures have made a substantial contribution to $\mathrm{SO}_{2}$ and $\mathrm{NO}_{\mathrm{x}}$ emission reductions in Europe as a whole. For individual countries, too, the importance of control measures is growing over time, or is expected to do so. Even if particular measures and standards are not introduced in all countries on the basis of environmental or other concerns, we expect that European countries will tend to become more similar in terms of controls applied in view of European integration. This is obvious for, e.g., international vehicle regulations, but will also apply to the design of modern power plants or industrial processes.

From the perspective of the recent climate change debate and the adoption of Europe's climate and energy package (EC 2008), it is essential to examine the factors that drive changes in European greenhouse gas emissions and contribute to uncertainty in emission projections (Lesiv et al. 2013, this issue). In addition, most air pollutants also act as precursors for short-lived climate forcers, e.g., sulphur aerosols, tropospheric ozone, black carbon. Therefore, addressing uncertainties associated with 
drivers of these emissions can enhance the understanding of potential near-term climate benefits (Shindell et al. 2012). For long-lived greenhouse gases such as $\mathrm{CO}_{2}$, the methodology presented in this paper provides a quantitative basis for the investigation of uncertainties related to determinants of emission trends in both the medium- and long-term. Similarly, the decomposition analysis can provide a set of input parameters necessary for uncertainty assessment of GHG-emission inventories.

Another phenomenon recognised in studies on factors behind changes in GHG emissions is that the ongoing relocation of manufacturing industries abroad contributed to slowing down growth rates of $\mathrm{CO}_{2}$ emissions in WEU during the past decade. Carbon emissions have in many cases leaked to countries with lower production costs, where some of the industrial activities are intended entirely for exports. As a result, national emissions of the importing country might be reduced without positive economic changes while being rather recorded and shifted elsewhere. However, global emissions do not decline in this context and the importation of goods manufactured overseas will eventually increase overall emissions (Peters and Hertwich 2008).

\section{Summary and conclusions}

The main objective of this study was to identify the principal factors responsible for reductions in air emissions. The work focuses on Europe, looking at 39 counties aggregated into two sub-regions (WEU and EEU), and develops long-term time series of emission data for sulphur dioxide $\left(\mathrm{SO}_{2}\right)$, nitrogen oxides $\left(\mathrm{NO}_{\mathrm{x}}\right)$ and carbon dioxide $\left(\mathrm{CO}_{2}\right)$. In five-year intervals, it looks at emissions from 1960 through 2010. Using publicly available energy and emission databases, emission trends and drivers behind their temporal evolution are quantified and evaluated for Europe.

The results show that over this fifty-year period $\mathrm{SO}_{2}$ and $\mathrm{NO}_{\mathrm{x}}$ emissions rose to historical peaks, but then declined below the 1960-70 baseline by 2010. Add-on control measures started to be introduced in the late 1980s, when international policy efforts also first began to take effect. For example, the first sulphur Protocol under the CLRTAP was adopted in 1985 (UN-ECE 1985), and a $\mathrm{NO}_{\mathrm{x}}$ Protocol followed in 1988 (UN-ECE 1988).

This study presents a methodology to isolate the main factors that influence air pollution emissions. The three pollutants examined here are strongly related to energy combustion, such that changes in energy use are key to understanding their evolution. The study distinguishes among four main determinants:

1a. Reduction of energy intensity;

1b. Improved conversion efficiency (the first two terms are aggregated for analysis);

3. Structural change as a shift of relative fuel shares; and

4. Control measures, targeted at the abatement of harmful effects of pollution.

For $\mathrm{SO}_{2}$, structural change has been the dominant factor in emission reductions, although the reduced energy intensity of some sectors has also played a role. By the end of the study period in 2010, about $25 \%$ of total reduction was attributed to targeted end-of-pipe abatement measures. In coming decades, the share of emission reductions due to control measures should rise as such measures penetrate the stock of existing capital and as more countries apply more advanced control measures.

For $\mathrm{NO}_{\mathrm{x}}$, structural change on the whole is less important. Emission-reducing structural change in the manufacturing industry and the power plant sector is outweighed by emission- 
increasing structural change in the transport sector. The application of control measures is the most important factor explaining emission reductions.

We identified reductions in energy intensity and fuel-saving measures as the decisive factor for mitigation of $\mathrm{CO}_{2}$ emissions during this timeframe. Changes in fuel mix contribute about one third of overall $\mathrm{CO}_{2}$ abatement. In the near future, the adoption of carbon capture might play a role in carbon mitigation as a factor belonging to the group of end-of-pipe measures (Lemoine et al. 2012). In many cases, global trade of goods also results in reductions of national carbon emissions due to the relocation of energy-intensive industries to countries with less efficient production. This in turn generates carbon leakage, wherein global $\mathrm{CO}_{2}$ emissions increase.

The relative importance of factors responsible for emission reductions differs between countries. Large differences appear between countries in WEU and EEU regions, reflecting different approaches in environmental and energy policies pursued. Over time, differences tend to diminish, which seems to be a good indication of the effectiveness of international environmental policies targeted at $\mathrm{SO}_{2}$ and $\mathrm{NO}_{\mathrm{x}}$ control in Europe.

One of the motivations for this study was to contribute to the understanding of the relationship between emissions and economic growth. The EKC hypothesis suggests that there is an inverted U-shaped relationship such that emissions first increase with economic growth and subsequently decrease once a certain level of wealth has been passed. Much debate remains about the reasons for such a relationship, if it exists. Two of the four factors identified in this study are clearly determined by economic parameters. Energy demand and efficiency gains ( $1 \mathrm{a}$ and $1 \mathrm{~b}$ above), which are aggregated into one term in our analysis, are related to economic growth and tend to exhibit a Kuznets-type dependency. Technological progress, although not modelled explicitly in this study, is also driven by economic factors, but it is less clear whether and how the pollution intensities of individual sectors are related to economic growth (Dolgopolova et al. 2013, this issue). Change in the share of different fuels ( 2 above) is also influenced by economic development; however, in many instances, this has, rather, been determined by the evolution of energy prices and direct policy interventions. That two of the main factors responsible for emission changes follow a Kuznets curve may be sufficient for such a relationship to also be observed between emission data (at least for some countries and some pollutants) and economic growth.

There is little evidence that the control measures ( 3 above) that played a substantial role in reducing air pollutants over the last two decades are directly linked to economic growth. Rather than being driven by an autonomous increase in prosperity, their implementation is triggered by enforcement of deliberate mitigation policies. Formal analysis of other potential relationships, or indeed the alternative hypothesis, that emission controls are related to some environmental factor, such as, for instance, deposition in excess of critical loads, ecosystem sensitivity or the transboundary nature of pollution, remains to be undertaken.

The results of this study may allow for different perspectives on future emission scenarios and associated uncertainties, as, for example, in Jonas et al. (2013, this issue). Forecasted emission reductions are mainly driven by control measures but there is substantial opportunity for emission-reducing structural and technological change. This could imply that emission reductions are more broadly and cheaply attainable than is presently expected. One should, however, avoid over-optimism. As there seems no autonomous mechanism to ensure that EKC-like patterns observed in the past will hold in the future, there is no guarantee that determinants responsible for emission abatement will continue to play the role they have in previous decades. Because structural change, energy consumption and technology respond to many driving forces other than environmental pressures, the possibility cannot be excluded that a period of emission-reducing pressures will be followed by a period of emission increasing changes. 
Acknowledgments The authors benefited from insights and discussions with J. Cofala and W. Schoepp from IIASA's Mitigation of Air Pollution \& Greenhouse Gases (MAG). We thank the reviewers for valuable comments and suggestions.

\section{References}

Amann M (1990) Energy use, emissions, and abatement costs. In: Alcamo J, Shaw R, Hordijk L (eds) The RAINS model of acidification, science and strategies in Europe. IIASA and Kluwer Academic Press, Dodrecht

Amann M, Bertok I, Cofala J, Heyes C, Klimont Z, Rafaj P, Schöpp W, Wagner F (2008) National emission ceilings for 2020 based on the 2008 climate \& energy package. NEC scenario analysis report \#6. International Institute for Applied Systems Analysis (IIASA), Laxenburg

Andreoni J, Levinson A (2001) The simple analytics of the environmental Kuznets curve. J Public Econ $80: 269-286$

Ang BW, Zhang FQ (2000) A survey of index decomposition analysis in energy and environmental studies. Energy 25:1149-1176. doi:10.1016/S0360-5442(00)00039-6

Barrett S, Frankel J, Victor D (2006) Climate treaties and "breakthrough" technologies. Am Econ Rev 96:2225. doi: $10.1257 / 000282806777212332$

Borken-Kleefeld J, Ntziachristos L (2012) The potential for further controls of emissions from mobile sources in Europe. TSAP report \#4. International Institute for Applied Systems Analysis (IIASA), Laxenburg

BP (2012) Statistical review of world energy 2012. London, UK. bp.com/statisticalreview

Bruvoll A, Medin H (2003) Factors behind the environmental Kuznets curve: a decomposition of the changes in air pollution. Environ Resour Econ 24:27-48

De Bruyn SM, Van Den Bergh JCJM, Opschoor JB (1998) Economic growth and emissions: reconsidering the empirical basis of environmental Kuznets curves. Ecol Econ 25:161-175

Capros P, Mantzos L, Papandreou V, Tasios N (2008) European energy and transport trends to 2030-update 2007. European Commission Directorate-General for Energy and Transport, Brussels

CIAM (2007) Review of the Gothenburg protocol. Report of the task force on integrated assessment modelling and the centre for integrated assessment modelling. Center for Integrated Assessment Modelling, Geneva

Cofala J, Bojarski W (1987) Emissions of sulphur and nitrogen oxides resulting from the energetic utilization of fuels - the situation in Poland. Kernforschungszentrum Karlsruhe, Karlsruhe

Cole MA (2000) Air pollution and "dirty" industries: how and why does the composition of manufacturing output change with economic development? Environ Resour Econ 17:109-123

Dekker T, Vollebergh HRJ, de Vries FP, Withagen CA (2012) Inciting protocols. J Environ Econ Manag 64:45-67. doi:10.1016/j.jeem.2011.11.005

Dolgopolova I, Hu B, Leopold A, Pickl S (2013) Economic, institutional and technological uncertainties of emissions trading - a system dynamics modeling approach. Clim Chang (this issue)

EC (1970) Council directive 70/220/EEC on the approximation of the laws of the Member States on measures to be taken against air pollution by emissions from motor vehicles. Commission of the European Communities, Brussels

EC (2001) Directive 2001/81/EC of the European Parliament and of the Council of 23 October 2001 on national emission ceilings for certain atmospheric pollutants. European Parliament and Council, Luxembourg

EC (2007) Regulation No 715/2007 on type-approval of motor vehicles with respect to emissions from light passenger and commercial vehicles (Euro 5 and Euro 6) and on access to vehicle repair and maintenance information. Commission of the European Communities, Brussels

EC (2008) Communication from the Commission to the European Parliament, the Council, the European Economic and Social Committee and the Committee of the Regions. 2020 by 2020: Europe's climate change opportunity. COM(2008) 30 final. Commission of the European Communities, Brussels

EMEP (2009) Transboundary, acidification, eutrophication and ground level ozone in Europe in 2007. Joint MSC-W \& CCC \& CEIP report. Norwegian Meterological Institute, Oslo

Grossman GM, Krueger AB (1995) Economic growth and the environment. Q J Econ 110:353-377

Gruver GW (1976) Optimal investment in pollution control capital in a neoclassical growth context. J Environ Econ Manag 3:165-177

Hoekstra R, van den Bergh JCJM (2003) Comparing structural and index decomposition analysis. Energy Econ 25:39-64. doi:10.1016/S0140-9883(02)00059-2 
Hordijk L, Amann M (2007) How science and policy combined to combat air pollution problems. Environ Policy Law 37:336-340

IEA (2009a) Energy balances of OECD countries 2009. International Energy Agency, IEA/OECD, Paris

IEA (2009b) Energy balances of non-OECD countries 2009. International energy agency, IEA/OECD, Paris

IEA (2009c) Energy statistics of OECD countries 2009. International Energy Agency, IEA/OECD, Paris

IEA (2009d) Energy statistics of non-OECD countries 2009. International Energy Agency, IEA/OECD, Paris

IEA (2010) $\mathrm{CO}_{2}$ Emissions from the fuel combustion, 2010th edn. International Energy Agency, IEA/OECD, Paris

Jonas M, Krey V, Wagner F, Marland G, Nahorski Z (2013) Uncertainty in in an emissions constrained world. Clim Chang (this issue)

Kaufmann RK, Davidsdottir B, Garnham S, Pauly P (1998) The determinants of atmospheric $\mathrm{SO}_{2}$ concentrations: reconsidering the environmental Kuznets curve. Ecol Econ 25:209-220

Kaya Y, Yokobori K (1997) Environment, energy, and economy: strategies for sustainability. United Nations University Press

Kohl WL (1982) After the second oil crisis: energy policies in Europe, America, and Japan. Lexington Books

Kuznets S (1955) Economic growth and income inequality. Am Econ Rev 45:1-28

Lemoine DM, Fuss S, Szolgayova J, Obersteiner M, Kammen DM (2012) The influence of negative emission technologies and technology policies on the optimal climate mitigation portfolio. Clim Chang 113:141162

Lesiv M, Bun A, Jonas M (2013) Analysis of change in relative uncertainty in GHG emissions from stationary sources for the EU 15. Clim Chang (this issue)

Markandya A, Golub A, Pedroso-Galinato S (2006) Empirical analysis of national income and $\mathrm{SO}_{2}$ emissions in selected European countries. Environ Resour Econ 35:221-257

Mylona S (1996) Sulphur dioxide emissions in Europe 1880-1991 and their effect on sulphur concentrations and depositions. Tellus Ser B Chem Phys Meteorol 48:662-689

Peters GP, Hertwich EG (2008) $\mathrm{CO}_{2}$ embodied in international trade with implications for global climate policy. Environ Sci Technol 42:1401-1407. doi:10.1021/es072023k

Rafaj P, Amann M, Cofala J, Sander R (2012) Factors determining recent changes of emissions of air pollutants in Europe. TSAP report \#2. International Institute for Applied Systems Analysis (IIASA), Laxenburg

Salameh MG (2004) Oil crises, historical perspective. Encycl Energy 633-648

Schöpp W, Posch M, Mylona S, Johansson M (2003) Long-term development of acid deposition (1880-2030) in sensitive freshwater regions in Europe. Hydrol Earth Syst Sci 7:436-446

Selden TM, Song D (1994) Environmental quality and development: is there a kuznets curve for air pollution emissions? J Environ Econ Manag 27:147-162

Selden TM, Song D (1995) Neoclassical growth, the J curve for abatement, and the inverted U curve for pollution. J Environ Econ Manag 29:162-168

Shafik N (1994) Economic development and environmental quality: an econometric analysis. Oxf Econ Pap 46:757-773

Shindell D, Kuylenstierna JCI, Vignati E, Van Dingenen R, Amann M, Klimont Z, Anenberg SC, Muller N, Janssens-Maenhout G, Raes F, Schwartz J, Faluvegi G, Pozzoli L, Kupiainen K, Höglund-Isaksson L, Emberson L, Streets D, Ramanathan V, Hicks K, Oanh NTK, Milly G, Williams M, Demkine V, Fowler D (2012) Simultaneously mitigating near-term climate change and improving human health and food security. Science 335:183-189

Stern DI (2004) The rise and fall of the environmental Kuznets curve. World Dev 32:1419-1439

Stern DI (2006) Reversal of the trend in global anthropogenic sulfur emissions. Glob Environ Chang 16:207-220

Stern DI, Common MS (2001) Is there an environmental Kuznets curve for sulfur? J Environ Econ Manag 41:162-178

UN-ECE (1985) Protocol to the 1979 convention on long-range transboundary air pollution on the reduction of sulphur emissions or their transboundary fluxes by at least 30 per cent. United Nations Economic Commission for Europe, Helsinki

UN-ECE (1987) National strategies and policies for air pollution abatement. United Nations, New York

UN-ECE (1988) Protocol to the 1979 convention on long-range transboundary air pollution concerning the control of emissions of nitrogen oxides or their transboundary fluxes. United Nations Economic Commission for Europe, Sofia

UN-ECE (1994) Protocol to the 1979 convention on long-range transboundary air pollution on further reduction of sulphur emissions. United Nations Economic Commission for Europe, Oslo

UN-ECE (1995) Strategies and policies for air pollution abatement-1994. Major review under the convention on long-range transboundary air pollution. United Nations Economic Commission for Europe, Geneva 
UN-ECE (1999) Protocol to the 1979 convention on long-range transboundary air pollution to abate acidification, eutrophication, and ground-level ozone. United Nations Economic Commission for Europe, Gothenburg

UNFCCC (1997) Kyoto protocol to the united nations framework convention on climate change. United Nations Framework Convention on Climate Change, Kyoto

UNFCCC (2009) 2009 GHG inventory submission from flexible GHG data queries. http://unfccc.int/di/ FlexibleQueries.do

Vestreng V, Myhre G, Fagerli H, Reis S, Tarrasón L (2007) Twenty-five years of continuous sulphur dioxide emission reduction in Europe. Atmos Chem Phys 7:3663-3681. doi:10.5194/acp-7-3663-2007

Viguier L (1999) Emissions of $\mathrm{SO}_{2}, \mathrm{NO}_{\mathrm{x}}$ and $\mathrm{CO}_{2}$ in transition economies: emission inventories and Divisia index analysis. Energy J 20:59-87

Waggoner P, Ausubel J (2002) A framework for sustainability science: a renovated IPAT identity. PNAS 99:7860-7865

World Bank (2013) Commodity price data. The World Bank Development Prospects Group, Washington 